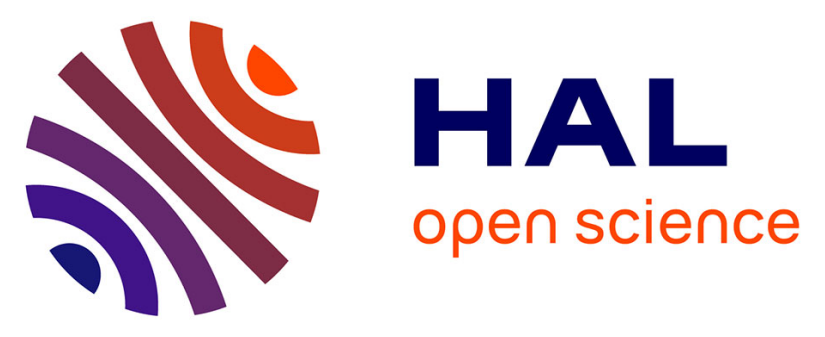

\title{
Intercomparison of Water Vapor Data Measured with Lidar during IHOP_2002. Part I: Airborne to Ground-Based Lidar Systems and Comparisons with Chilled-Mirror Hygrometer Radiosondes
}

Andreas Behrendt, Volker Wulfmeyer, Hans-Stefan Bauer, Thorsten Schaberl, Paolo Di Girolamo, Donato Summa, Christoph Kiemle, Gerhard Ehret, David Whiteman, Belay Demoz, et al.

\section{- To cite this version:}

Andreas Behrendt, Volker Wulfmeyer, Hans-Stefan Bauer, Thorsten Schaberl, Paolo Di Girolamo, et al.. Intercomparison of Water Vapor Data Measured with Lidar during IHOP_2002. Part I: Airborne to Ground-Based Lidar Systems and Comparisons with Chilled-Mirror Hygrometer Radiosondes. Journal of Atmospheric and Oceanic Technology, 2007, 24 (1), pp.3-21. 10.1175/JTECH1924.1 . insu-03533102

\section{HAL Id: insu-03533102 \\ https://hal-insu.archives-ouvertes.fr/insu-03533102}

Submitted on 20 Jan 2022

HAL is a multi-disciplinary open access archive for the deposit and dissemination of scientific research documents, whether they are published or not. The documents may come from teaching and research institutions in France or abroad, or from public or private research centers.
L'archive ouverte pluridisciplinaire HAL, est destinée au dépôt et à la diffusion de documents scientifiques de niveau recherche, publiés ou non, émanant des établissements d'enseignement et de recherche français ou étrangers, des laboratoires publics ou privés.

$$
\text { Copyright }
$$




\title{
Intercomparison of Water Vapor Data Measured with Lidar during IHOP_2002. Part I: Airborne to Ground-Based Lidar Systems and Comparisons with Chilled-Mirror Hygrometer Radiosondes
}

\author{
Andreas Behrendt, ${ }^{*}$ Volker Wulfmeyer, ${ }^{*}$ Paolo Di Girolamo, ${ }^{+}$Christoph Kiemle, ${ }^{*}$ \\ Hans-Stefan Bauer,* Thorsten Schaberl, ${ }^{*}$ Donato Summa, ${ }^{+}$David N. Whiteman, ${ }^{@}$ \\ Belay B. Demoz, @ Edward V. Browell, \& Syed Ismail, \& Richard Ferrare, \& Susan Kooi, \& \\ GERHARD EHRET, ${ }^{\#}$ AND JUNHONG WANG** \\ *Institut für Physik und Meteorologie, Universität Hohenheim, Stuttgart, Germany \\ + Università degli Studi della Basilicata, Potenza, Italy \\ \# Deutsches Zentrum für Luft- und Raumfahrt (DLR), Oberpfaffenhofen, Germany \\ @ Mesoscale Atmospheric Processes Branch, NASA GSFC, Greenbelt, Maryland \\ \& NASA Langley Research Center, Hampton, Virginia \\ **Atmospheric Technology Division, National Center for Atmospheric Research, Boulder, Colorado
}

(Manuscript received 24 August 2005, in final form 6 December 2005)

\begin{abstract}
The water vapor data measured with airborne and ground-based lidar systems during the International $\mathrm{H}_{2} \mathrm{O}$ Project (IHOP_2002), which took place in the Southern Great Plains during 13 May-25 June 2002 were investigated. So far, the data collected during IHOP_2002 provide the largest set of state-of-the-art water vapor lidar data measured in a field campaign. In this first of two companion papers, intercomparisons between the scanning Raman lidar (SRL) of the National Aeronautics and Space Administration (NASA) Goddard Space Flight Center (GSFC) and two airborne systems are discussed. There are 9 intercomparisons possible between SRL and the differential absorption lidar (DIAL) of Deutsches Zentrum für Luftund Raumfahrt (DLR), while there are 10 intercomparisons between SRL and the Lidar Atmospheric Sensing Experiment (LASE) of the NASA Langley Research Center. Mean biases of $(-0.30 \pm 0.25) \mathrm{g} \mathrm{kg}^{-1}$ or $-4.3 \% \pm 3.2 \%$ for SRL compared to DLR DIAL (DLR DIAL drier) and $(0.16 \pm 0.31) \mathrm{g} \mathrm{kg}^{-1}$ or $5.3 \%$ $\pm 5.1 \%$ for SRL compared to LASE (LASE wetter) in the height range of $1.3-3.8 \mathrm{~km}$ above sea level (450-2950 $\mathrm{m}$ above ground level at the SRL site) were found. Putting equal weight on the data reliability of the three instruments, these results yield relative bias values of $-4.6 \%,-0.4 \%$, and $+5.0 \%$ for DLR DIAL, SRL, and LASE, respectively. Furthermore, measurements of the Snow White (SW) chilled-mirror hygrometer radiosonde were compared with lidar data. For the four comparisons possible between SW radiosondes and SRL, an overall bias of $(-0.27 \pm 0.30) \mathrm{g} \mathrm{kg}^{-1}$ or $-3.2 \% \pm 4.5 \%$ of SW compared to SRL (SW drier) again for 1.3-3.8 km above sea level was found. Because it is a challenging effort to reach an accuracy of humidity measurements down to the $\sim 5 \%$ level, the overall results are very satisfactory and confirm the high and stable performance of the instruments and the low noise errors of each profile.
\end{abstract}

\section{Introduction}

The International $\mathrm{H}_{2} \mathrm{O}$ Project (IHOP_2002) took place over the Southern Great Plains of the United States from 13 May to 25 June 2002 (Weckwerth et al. 2004). The main objective of this field campaign was to

Corresponding author address: Dr. Andreas Behrendt, Institut für Physik und Meteorologie, Universität Hohenheim, Stuttgart D-70593, Germany.

E-mail: behrendt@uni-hohenheim.de determine if improved measurements of water vapor lead to a corresponding improvement in our ability to predict convective rainfall amounts. The IHOP_2002 region (Fig. 1) in the central United States was an optimal location due to existing experimental and operational facilities, strong variability in moisture, and active convection initiation.

IHOP_2002 comprised four main research components: 1) quantitative precipitation forecasting, which used a variety of forecasting models to determine if better humidity measurements would improve the models' ability to forecast rainfall; 2) convective initia-

DOI: 10.1175/JTECH1924.1 


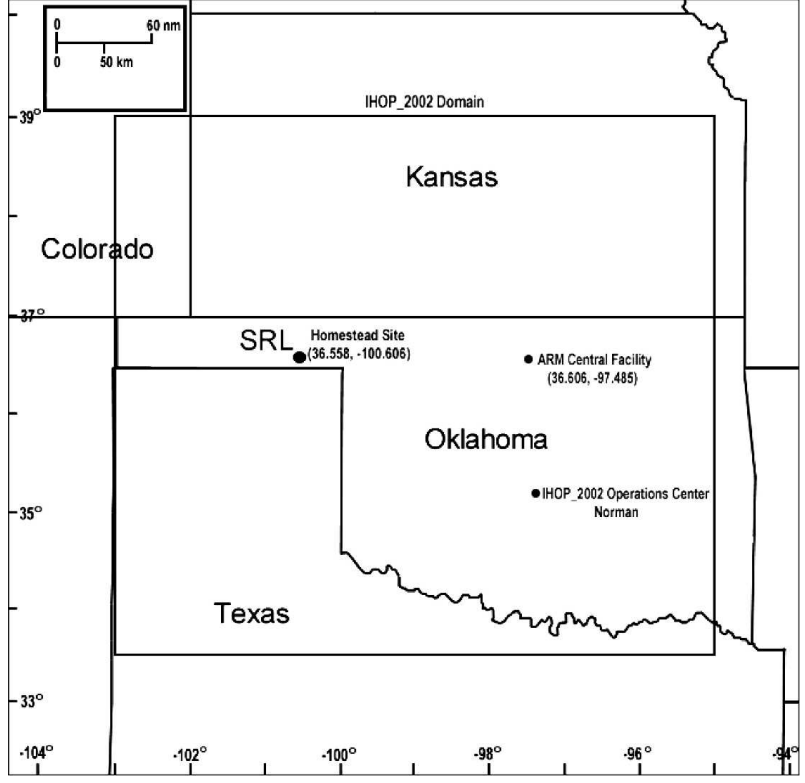

FIG. 1. IHOP_2002 operations domain and instrumentation sites. The SRL was located at the Homestead Profiling Site while the airborne DIAL systems were operated in different altitudes with focus on the marked rectangular domain.

tion, which used humidity measurements made before the storms to investigate whether these can help in forecasting the timing and location of new storms; 3 ) atmospheric boundary layer (ABL), which studied the relationship between land surface variations and the moisture budget in the ABL; and 4) instrumentation, which determined the best combination of instruments for the characterization of the four-dimensional water vapor field.

The specific feature of the IHOP_2002 campaign was its extraordinary collection and simultaneous application of the most advanced ground-based and airborne passive and active water vapor remote sensing systems. Most of these systems had an unprecedented resolution and accuracy from close to the ground up to the midtroposphere so that new insights in atmospheric processes were expected. Of special interest in this context were water vapor lidar systems because they provide data with high resolution, and, when applied on an airborne platform, large spatial coverage. The accuracy of these instruments is typically very high. However, when applied under rough conditions in the field, special care has to be taken to control their performance. A further step lies then in verifying the error estimates of the data, which have passed the internal quality check of each instrument. The IHOP_2002 dataset provided one of the rare opportunities to intercompare the data of today's state-of-the-art water vapor lidar systems.

Five water vapor lidar systems participated in
IHOP_2002. Three of these, which were all based on the differential absorption lidar (DIAL) technique (Schotland 1966; Bösenberg 1998), were operated on airborne platforms: the DIAL of the German Aerospace Center [Deutsches Zentrum für Luft- und Raumfahrt (DLR)], the Lidar Atmospheric Sensing Experiment (LASE) of the National Aeronautics and Space Administration (NASA) Langley Research Center, and the Lidar Embarque pour l'etude des Aerosols et des Nuages, de l'interaction Dynamique-Rayonnement et du cycle de l'Eau (LEANDRE II) of the Centre National de la Recherche Scientifique (CNRS), Paris, France. Two water vapor lidar systems were operated on the ground, both using the Raman lidar technique (see for a recent review, e.g., Wandinger 2005): the Scanning Raman Lidar (SRL) of NASA Goddard Space Flight Center (GSFC; Whiteman et al. 2006a,b) and the Cloud and Radiation Testbed Raman Lidar (CARL; Turner et al. 2000, 2002).

The collected dataset will be applied for the validation and initialization of models as well as for data assimilation; a first study has just been performed in which IHOP_2002 data of LASE were assimilated with four-dimensional data variation (4DVAR) into the fifth-generation Pennsylvania State UniversityNational Center for Atmospheric Research (PSUNCAR) Mesoscale Model (MM5) demonstrating the high potential of lidar in this context (Wulfmeyer et al. 2006). A prerequisite for using lidar data for data assimilation is their detailed characterization with respect to accuracy, noise errors, and resolution. As a result, these investigations will lead to an improvement of the parameterization of convection and cloud development in models of different scales.

The objective of this paper is to provide error estimates of the data of three instruments during IHOP_2002: DLR DIAL, LASE, and SRL. With the available dataset, the numbers of possible intercomparisons of airborne to ground-based systems with LEANDRE II and with CARL are unfortunately too small to derive conclusions on the instrumental performances during IHOP_2002. It is helpful in this context that the water vapor measurement performance of CARL relative to the SRL, radiosondes, and LASE has been analyzed during previous campaigns (Ferrare et al. 2002, 2004; Revercomb et al. 2003). A list of all intercomparison cases between all five lidar instruments during IHOP_2002 can be found in (Behrendt et al. 2004). In a companion paper (Behrendt et al. 2007, hereafter Part II), we discuss intercomparisons of the three water vapor DIAL systems operated during IHOP_2002, which were all operated on airborne platforms and derive the mutual bias between LEANDRE 
II and DLR DIAL water vapor data with the use of data of a formation flight.

This paper is organized as follows. In section 2, we describe which criteria we used to identify possible intercomparisons between the lidar instruments. Short descriptions of the instruments are given in section 3 . How the comparisons were performed (i.e., which formulas are used to calculate bias and root-mean-square deviations) is described in section 4. Sections 5 and 6 discuss the results of intercomparisons between SRL and LASE, as well as between SRL and DLR DIAL data, respectively, while section 7 shows the intercomparison results between SRL and chilled-mirror hygrometer radiosondes. The overall results are discussed in section 8, and a summary and conclusions are given in section 9 .

\section{Intercomparison tables}

The three airborne water vapor DIAL systems operated during IHOP_2002 were mounted on the following aircrafts: the DIAL of DLR (Ehret et al. 1993; Poberaj et al. 2002) on the Falcon of DLR, LEANDRE II of CNRS Service Aeronomie (Bruneau et al. 2001) on the P3 of the Naval Research Laboratory, and LASE of NASA Langley (Browell and Ismail 1995) on the DC-8 of NASA. The two ground-based water vapor Raman lidar systems, SRL of NASA GSFC and CARL of the Department of Energy (DOE) Atmospheric Radiation Mission (ARM) were located at the Homestead Profiling Site $\left(36.558^{\circ} \mathrm{N}, 100.606^{\circ} \mathrm{W}\right)$ and the ARM Central Facility $\left(36.606^{\circ} \mathrm{N}, 97.485^{\circ} \mathrm{W}\right)$ both in Oklahoma (Fig. $1)$, respectively. For all flight tracks performed during IHOP_2002, we calculated the distances between the five water vapor lidar systems.

To identify possible intercomparisons, we tentatively set a fixed cutoff distance between the footprint of the airborne DIAL systems and the ground-based Raman lidars of $20 \mathrm{~km}$. Obviously, the comparability of the data generally depends on the meteorological conditions, particularly the horizontal variability of the water vapor field, as well as the orientation of the aircrafts with respect to the mean wind. By the investigation of water vapor time-height cross sections measured with the different DIAL systems it was found that a distance of $20 \mathrm{~km}$ was a reasonable maximum limit, which corresponds to about 1.5-min flight time of the DC-8, the fastest airplane operated, carrying LASE. For larger distances in space and time, the natural heterogeneity of the atmospheric water vapor field in the lower troposphere was generally too large to draw conclusions on instrumental performances. But also within a $20-\mathrm{km}$ distance, often large, natural differences in the humid- ity field occur so that conclusions based on instrumental biases can only be derived from a larger number of independent intercomparisons between two instruments. The $20-\mathrm{km}$ criterion was found to be a good compromise for the IHOP_2002 dataset because the horizontal resolution of the data is similar to this distance (LASE data are available with 1-min temporal resolution) and the resulting numbers of possible comparisons were large enough for a statistical analysis. That for airborne-to-airborne intercomparisons in addition to these points special considerations have to be applied, is discussed in a companion paper (Part II).

After preliminary tables were set up with the $20-\mathrm{km}$ criteria, we checked whether the different sensors were operating and had collected data with good quality (i.e., whether the data had passed the internal quality control of each instrument). Finally, the operation modes were taken into account (e.g., LEANDRE II pointing in a horizontal or nadir direction).

\section{Lidar systems used in this study}

\section{a. DLR DIAL}

At the DLR, airborne water vapor DIAL systems have been operated since 1989 (Ehret et al. 1993). The first water vapor DIAL operated in the near-infrared spectral region at $724 \mathrm{~nm}$ and was routinely installed nadir-viewing on board the DLR's meteorological research aircraft Falcon 20. To increase both accuracy and spatial resolution as well as the sensitivity for water vapor measurements in the stratosphere, a new water vapor DIAL system was developed at DLR in the early 1990s. Based on a high peak and average power optical parametric oscillator (OPO), its transmitter fulfills the stringent spectral requirements for precise water vapor DIAL measurements in the troposphere as well as in the stratosphere (Ehret et al. 1998; Poberaj et al. 2002). The transmitter is designed to be operated at either the weak $4 \nu$ vibrational absorption bands of water vapor near $925 \mathrm{~nm}$, which is suitable for tropospheric measurements or at the one order of magnitude stronger $3 v$ vibrational absorption band lying in the 940-nm spectral region. The new DLR water vapor DIAL, which is here referred to as the DLR DIAL, has already demonstrated its readiness for airborne water vapor measurements (Ehret et al. 1999; Poberaj et al. 2002). During the major field campaign Mesoscale Alpine Program (MAP'99) the system successfully operated on a long-term basis of more than 40 flight hours on board the Falcon 20.

For IHOP_2002, the new 100-Hz DIAL system was used and tuned to the water vapor absorption line at $926.87403 \mathrm{~nm}$. To derive water vapor number density 
with the DIAL technique (Bösenberg 1998), spectral parameters from the High-Resolution Transmission molecular absorption database (HITRAN_2001) were taken. Temperature data from the nearest available dropsonde or radiosonde were then used to derive water vapor mixing ratio values from the measured water vapor number density (see section 4 for details). The system was pointing in nadir and was flown at an eyesafe height of typically $3-4 \mathrm{~km}$. Within the range of 0 to approximately $200 \mathrm{~m}$ below flight level, the measurement of water vapor was not possible, otherwise the measurement range covered the lower free troposphere and the boundary layer down to approximately $200 \mathrm{~m}$ above ground.

With the instrumental setting used during IHOP_2002, the DLR DIAL was expected to have a statistical uncertainty of $0.5 \%$ at vertical and horizontal resolutions of 200 and $1500 \mathrm{~m}$ for measurements at 2.5 $\mathrm{km}$ ASL (i.e., $1.5 \mathrm{~km}$ below the aircraft in the so-called near range), and at an aircraft speed of about $150 \mathrm{~m} \mathrm{~s}^{-1}$. At $0.3 \mathrm{~km}$ ASL (i.e., $3.7 \mathrm{~km}$ below the aircraft in the far range) the statistical uncertainty increases to about $3.4 \%$ for the same resolutions. The overall accuracy of the measurements were estimated to be about $5 \%$ and $9 \%$ in the near and far range, respectively, which includes all systematic errors except the uncertainty of the absorption cross section and contributions of the Rayleigh Doppler effect.

The DLR DIAL was operated on 21 flights during IHOP_2002 from 17 May to 15 June 2002.

\section{b. $L A S E$}

NASA's LASE is an airborne DIAL system used to measure water vapor, aerosols, and clouds throughout the troposphere. LASE was operated during IHOP_2002 on eight flights from 23 May to 14 June 2002.

LASE uses a double-pulsed Ti:sapphire laser, which is pumped by a frequency-doubled flashlamp-pumped Nd:YAG laser, to transmit light in the 815-nm absorption band of water vapor. The Ti:sapphire laser wavelength is controlled by injection seeding with a diode laser that is frequency locked to a water vapor line using an absorption cell. LASE operates by locking onto a strong water vapor line and electronically tuning to any spectral position on the absorption line to choose the suitable absorption cross section for optimum measurements over a range of water vapor concentrations in the atmosphere. During IHOP_2002, LASE operated from the NASA DC-8 using strong and weak water vapor lines in both the nadir and zenith modes, thereby simultaneously acquiring data below and above the aircraft. The strongly absorbing, temperature insen- sitive water vapor line at $817.2231 \mathrm{~nm}(12236.5603$ $\mathrm{cm}^{-1}$ ) with a line strength of $4.060 \times 10^{-23} \mathrm{~cm}$, line width of $0.0839 \mathrm{~cm}^{-1}$, and lower energy state of 224.838 $\mathrm{cm}^{-1}$ was used during IHOP_2002. Line strength accuracy is estimated to be $2 \%$ and line widths have agreed with other measurements to within $2 \%$ giving an overall accuracy of absorption cross section of better than $3 \%$ (Ponsardin and Browell 1997). Effective absorption cross-section profiles were calculated at the online and offline wavelengths and the sideline positions, and corrections for Doppler broadening, pressure shift, water vapor line width, spectral purity, molecular density, and aerosol scattering ratio were used in water vapor mixing ratio retrievals (Ismail and Browell 1989).

Humidity profiles were derived from the LASE measurements across the troposphere from 0 to $12 \mathrm{~km}$ over a mixing ratio range of about $20-0.01 \mathrm{~g} \mathrm{~kg}^{-1}$. For deriving water vapor mixing ratio values from the DIAL measurements, an average air density profile retrieved from all the radiosondes launched near the CART site and all the dropsondes from the Learjet and Falcon aircrafts during the DC-8 flight were used.

The water vapor profiles were retrieved using a vertical resolution of about $330 \mathrm{~m}$ for altitudes above 330 $\mathrm{m}$ above ground level and a horizontal resolution (along the flight direction) of $14 \mathrm{~km}$. Vertical and horizontal running averages were performed on raw LASE data with $30-\mathrm{m}$ vertical and 6 -s $(\sim 1.4 \mathrm{~km})$ horizontal resolutions. For DC-8 altitudes near $8 \mathrm{~km}$, a combination of the line center and sideline (at spectral separation of about $+18 \mathrm{pm}$ from the line center) positions were used to measure water vapor mixing ratios in the range of $0.1-1.0$ and 1.0 to $>15 \mathrm{~g} \mathrm{~kg}^{-1}$, respectively.

Precision of LASE water vapor measurements was estimated to be between 3\% and 5\% and total systematic errors are also estimated to be in the 3\%-5\% range (Ismail and Browell 1989) giving the overall accuracy of LASE measurements in the $5 \%-10 \%$ range. Previous water vapor comparisons have shown that LASE water vapor mixing ratio measurements have a typical accuracy of better than $6 \%$ or $0.01 \mathrm{~g} \mathrm{~kg}^{-1}$, whichever is larger, across the troposphere (Browell et al. 1997).

\section{c. Scanning Raman lidar}

The NASA GSFC SRL is a mobile ground-based system contained in a single environmentally controlled trailer. It includes a Nd:YAG laser, 0.76-m telescope, and a large aperture scanning mirror. Using Raman scattering from atmospheric molecules, the SRL system measures high-temporal and high-spatial resolution profiles of aerosol backscattering/extinction and water vapor mixing ratio profiles during the daytime and nighttime. 
Derived products from the system include water vapor mixing ratio, aerosol extinction and backscattering, cloud liquid water, cloud droplet radius and number density (under certain conditions), and cloud-base height. The UV transmission windows permit measurements during rainfall. A detailed description of SRL and an overview of its performance and measurements during IHOP_2002 can be found in Whiteman and Melfi (1999) and Whiteman et al. (2006a,b). In this campaign, also a rotational Raman lidar receiver for temperature measurements was temporarily added to SRL (Di Girolamo et al. 2004).

The SRL was located at the Homestead Profiling Site near the S-Pol radar. The system can be scanned continuously from horizon to horizon or in a mode that allows vertical measurements and measurements at $5^{\circ}-$ $10^{\circ}$ above the horizon in either direction (limited by eye-safety issues), with the scanning axis being eastwest. Most of the IHOP_2002 measurements of SRL were made pointing vertically to enable high-resolution studies of boundary layer turbulence. For the present intercomparison study, only vertical profiles were used.

The SRL was operated for approximately 40 days during IHOP_2002. The instrument is not automated and, based on a crew of two people, approximately 8-h measurement periods on any given experiment day were accomplished. Measurements were performed both at daytime and nighttime. In contrast to previous intercomparison studies using preliminary SRL data (Behrendt et al. 2004; Sabatino et al. 2004), we used reprocessed SRL data (revisions 4, released 2 August 2004). For these SRL data, a mean calibration constant was determined using all the vertical SRL datasets from IHOP_2002.

The water vapor data of SRL have been processed using a single, height-independent calibration constant determined from the updated processing of the SuomiNet GPS data [except for three dates $(14,17$, and 18 June) that were not used for the lidar-to-lidar intercomparisons of this study]. The analysis of the calibration constant yielded a standard deviation of the calibration constant for all the SRL data of $\sim 6 \%$. When using only daytime measurements, the standard deviation is $\sim 6.5 \%$ while it is $\sim 4.5 \%$ when using only nighttime measurements. The smaller standard deviation of the calibration constant for nighttime measurements is probably due to increased horizontal homogeneity of the atmospheric water vapor field at night, which gives a better agreement between the water vapor profile in a vertical column measured with the lidar and the volume average measured with GPS. The daytime and nighttime calibration constants differ by $\sim 1 \%$, indicating no significant diurnal bias in the SRL water vapor measurements. The data of Release 4 are in general drier than the preliminary releases of 10 June 2003 and 5 December 2003 by approximately 3\% in the boundary layer.

In lidar systems, measurements are generally more difficult in the very near field where the overlap between the transmitted laser beam and the field of view of the receiver telescope is not total. The SRL data include corrections for the system overlap function and the temperature dependence of water vapor and nitrogen Raman scattering (Whiteman et al. 1992; Whiteman 2003a,b). The overlap correction was determined based on an ensemble of comparisons with total precipitable water-corrected radiosondes launched at the Homestead Profiling Site. The overlap correction influences the data in the lowest $750 \mathrm{~m}$ above the system and increases from $0 \%$ to approximately $6 \%$ at $300 \mathrm{~m}$ above ground level, which is equivalent to $1162 \mathrm{~m}$ above sea level (ASL; height of SRL was $862 \mathrm{~m}$ ASL during IHOP_2002). Only a few datasets had to be truncated at higher altitudes. Sliding-window averages in the vertical and temporal domains have been applied for the water vapor data with lengths of $3 \mathrm{~min}$ and $90 \mathrm{~m}$ for heights above ground level of $0-1 \mathrm{~km}, 150 \mathrm{~m}$ for 1-2 $\mathrm{km}, 210 \mathrm{~m}$ for $2-3 \mathrm{~km}, 270 \mathrm{~m}$ for $3-4 \mathrm{~km}$, and $330 \mathrm{~m}$ above $4 \mathrm{~km}$. The resulting water vapor data resolution, determined by the half-power point in a Fourier spectral analysis, is approximately 2-min temporal for the water vapor data. In the vertical, the approximate resolutions are for $0-1 \mathrm{~km}: 60 \mathrm{~m}, 1-2 \mathrm{~km}: 100 \mathrm{~m}, 2-3 \mathrm{~km}$ : $150 \mathrm{~m}, 3-4 \mathrm{~km}: 180 \mathrm{~m},>4 \mathrm{~km}: 210 \mathrm{~m}$. The data are provided at 1-min intervals and in 30-m altitude steps. The vertical range is $5 \mathrm{~km}$ for daytime and $12 \mathrm{~km}$ for nighttime. Based on 3-min time averaging, the random error of water vapor mixing ratio is usually between $10 \%$ and $15 \%$ below $4 \mathrm{~km}$ for daytime operation and $2 \%$ for nighttime operation. The exact value of each individual profile depends then on the atmospheric conditions present. The statistical uncertainty of each SRL water vapor profile is derived with the intensity of the lidar signals using Poisson statistics and is provided with the water vapor data at the IHOP_2002 database.

\section{Intercomparisons: Root-mean-square deviation and bias}

To describe the deviations between the measurements of two sensors, we calculated the bias and rootmean-square (RMS) deviations of the water vapor mixing ratio data according to the following formulas:

$$
\operatorname{Bias}_{i, \text { absolute }}\left(z_{1}, z_{2}\right)=\frac{\sum_{z=z_{1}}^{z_{2}}\left[q_{1}(z)-q_{2}(z)\right]}{N_{z}},
$$




$$
\begin{aligned}
\operatorname{Bias}_{i, \text { relative }}\left(z_{1}, z_{2}\right) & =\frac{2 \sum_{z=z_{1}}^{z_{2}}\left[q_{1}(z)-q_{2}(z)\right]}{\sum_{z=z_{1}}^{z_{2}}\left[q_{1}(z)+q_{2}(z)\right]}, \\
\operatorname{RMS}_{i, \text { absolute }}\left(z_{1}, z_{2}\right) & =\sqrt{\frac{\sum_{z=z_{1}}^{z_{2}}\left[q_{1}(z)-q_{2}(z)\right]^{2}}{N_{z}}},
\end{aligned}
$$

$$
\operatorname{RMS}_{i, \text { relative }}\left(z_{1}, z_{2}\right)=\frac{\sqrt{\frac{\sum_{z=z_{1}}^{z_{2}}\left[q_{1}(z)-q_{2}(z)\right]^{2}}{N_{z}}}}{\frac{\sum_{z=z_{1}}^{z_{2}}\left[q_{1}(z)+q_{2}(z)\right]}{2 N_{z}}},
$$

where $i$ is an index denoting the intercomparison number; $q_{1}$ and $q_{2}$ are the water vapor mixing ratio values of the two sensors in the height $z ; z_{1}$ and $z_{2}$ are the lower and upper boundary of the height interval considered, respectively; and $N_{z}$ is the number of data points for each sensor in this interval. To calculate relative bias and relative RMS deviation, the values of absolute bias and absolute RMS deviation are divided by the mean concentration. Here the mean of the data of the two instruments is used and not just the data of one of the instruments. This procedure results in more objective values than defining one of the sensors as the sole reference.

The bias identifies an offset between two sensors that is constant in time; biases for different height intervals show a height dependence of a constant offset (e.g., due to temperature- or pressure-dependent effects of either the Raman backscatter cross section or water vapor absorption cross section, or effects caused by the partial overlap of laser beam and receiver). In contrast to this, the RMS deviation includes all differences of the compared data (i.e., systematic and statistical deviations as well as natural differences of the water vapor contained in the air masses sampled by the two compared sensors). The contribution of natural differences can be minimized by decreasing the distance of the locations where measurements are performed, but they cannot be avoided when field measurements are performed. This is because the typical diameter of the laser beam transmitted by lidar instruments, which is equivalent to the diameter of the sampled air column, ranges from just a few centimeters to a few meters depending on the individual system and range. Therefore, the RMS deviation quantifies an upper limit for the sum of the statistical uncertainties of the two compared instruments (i.e., systematic differences as well as the natural variability of the atmosphere).

We decided to use $500 \mathrm{~m}$ as the length of the height intervals $\left(z_{1}, z_{2}\right)$ in this study. This window length seems to us as a good compromise here because, on the one hand, this resolution is large enough compared with the effective resolution of the water vapor data to allow independent comparisons for the 500-m intervals, on the other hand, $500 \mathrm{~m}$ is small enough to investigate height dependencies of the deviations.

For the intercomparisons with SRL, we decided to put the bottom height to $1.3 \mathrm{~km}$ ASL, which is equivalent to about $450 \mathrm{~m}$ above ground level (the exact height of SRL was $862 \mathrm{~m} \mathrm{ASL}$ ) and evaluate the data in five height intervals up to $3.8 \mathrm{~km}$ ASL (2938 m above ground level). In consequence, the selected intervals cover the planetary boundary layer and lower free troposphere of the data used in this comparison study. For heights lower than $1.3 \mathrm{~km}$ ASL, we found that too many data points of at least one instrument were missing to obtain useful statistical information. In addition to the 500-m-interval deviations, we calculated biases and RMS deviations also for the whole $2.5-\mathrm{km}$ interval between 1.3 and $3.8 \mathrm{~km}$ ASL. In cases where either of the sensors did not provide data over the full length of a height interval (for a few cases at the bottom or top interval near 1.3 and $3.8 \mathrm{~km}$ ASL, respectively), we decided nevertheless to take into account the available data only covering parts of the intervals.

With the total number of possible intercomparison cases between two sensors, we computed afterward the mean bias and RMS deviation for each 500-m height interval and the total $2.5-\mathrm{km}$ interval with

$$
\bar{X}\left(z_{1}, z_{2}\right)=\frac{\sum_{i} X_{i}\left(z_{1}, z_{2}\right)}{N_{i}},
$$

where $X$ denotes the RMS or bias in absolute or relative values, respectively, calculated with Eqs. (1)-(4) and $N_{i}$ is the number of possible intercomparison cases. Furthermore, we calculated the standard deviations of this mean.

While water vapor Raman lidar directly measures the water vapor mixing ratio, water vapor DIAL measures the water vapor number concentration $n_{\mathrm{H} 2 \mathrm{O}}$ (i.e., the number of $\mathrm{H}_{2} \mathrm{O}$ molecules per volume). The water vapor mixing ratio $q_{\mathrm{H} 2 \mathrm{O}}\left(\right.$ in $\left.\mathrm{kg} \mathrm{kg}^{-1}\right)$ is then calculated with 


$$
q_{\mathrm{H} 2 \mathrm{O}}=\left(\frac{p}{m_{\mathrm{H} 2 \mathrm{O}} n_{\mathrm{H} 2 \mathrm{O}} R T}-1.6078\right)^{-1} \mathrm{~kg} \mathrm{~kg}^{-1}
$$

where $m_{\mathrm{H} 2 \mathrm{O}}$ is the molecular mass of $\mathrm{H}_{2} \mathrm{O}, R=0.28704$ $\mathrm{J}(\mathrm{g} \mathrm{K})^{-1}$ is the special gas constant for dry air, $p$ is pressure, and $T$ is temperature (e.g., Warnecke 1997). Here $p$ and $T$ are usually taken from collocated radiosonde measurements or from models (see section 3 for details). We decided to compare water vapor mixing ratio data in this study because these are the data collected on the IHOP_2002 data server for atmospheric studies and it is important to assess their systematic and noise errors. It can be seen that relative errors of $q$ scale approximately with relative errors of $T$. Thus, an error of $1 \mathrm{~K}$ at a temperature of $250 \mathrm{~K}$ results in an error of $\sim 0.4 \%$ when deriving mixing ratio values from water vapor DIAL measurements. It is obvious that this source of errors may be further reduced by simultaneous temperature measurements in the same air masses. Such measurements are also possible with lidar (Behrendt and Wulfmeyer 2003; Behrendt 2005).

\section{Intercomparisons of SRL and DLR DIAL}

An overview of possible intercomparisons between the SRL and the DLR DIAL is given in Table 1. All approaches of the DLR-Falcon to the SRL location closer than $20 \mathrm{~km}$ with measurement data available are listed. In total, nine profile-to-profile intercomparisons could be performed (eight with the data of 29 May 2002 and one for 9 June 2002). These nine intercomparison cases can be divided in two subgroups: there are four intercomparisons possible with small minimum distances of $0.4-0.6 \mathrm{~km}$ and five intercomparisons with larger minimum distances of $15.4-18.5 \mathrm{~km}$.

Figure 2 shows as example the data of the intercomparison case with a minimum distance between the DLR DIAL footprints and SRL of $0.4 \mathrm{~km}$, which is the smallest value of the possible intercomparison cases. To compute deviations, we arbitrarily decided to interpolate SRL data to DLR DIAL data heights. The differences at single heights between the water vapor mixing ratio measured with DLR DIAL and SRL are mostly smaller than $10 \%$ or $0.5 \mathrm{~g} \mathrm{~kg}^{-1}$. Exceptions are found at the bottom and top heights where the statistical uncertainty of the data is largest and near the boundary layer top where natural inhomogeneities of the water vapor field and the effect of different vertical and horizontal averaging lengths are most significant. The height of the boundary layer top differs by only $\sim 100 \mathrm{~m}$, which
TABLE 1. Intercomparisons between SRL and DLR DIAL (approaches to the Homestead Profiling Site with less than 20-km distance). The time given is for the DLR DIAL data file that was taken while the DLR Falcon was closest to the SRL (minimum distance), RMS difference of DLR DIAL and SRL humidity measurements averaged over those heights between 1.3 and $3.8 \mathrm{~km}$ ASL ( $\sim 0.45$ to $\sim 2.95 \mathrm{~km}$ above ground level at the Homestead Profiling Site) where both instruments provided data. Intercomparison cases with minimum distances $<1 \mathrm{~km}$ are in bold.

\begin{tabular}{|c|c|c|c|c|c|}
\hline No. & Date & $\begin{array}{l}\text { Time } \\
\text { (UTC) }\end{array}$ & $\begin{array}{c}\text { Min } \\
\text { distance } \\
(\mathrm{km})\end{array}$ & $\begin{array}{c}\text { Mean bias, } \\
\text { DLR SRL, } \\
1.3-3.8 \mathrm{~km} \\
\quad(\%)\end{array}$ & $\begin{array}{c}\text { Mean RMS } \\
\text { deviation } \\
1.3-3.8 \mathrm{~km} \\
(\%)\end{array}$ \\
\hline 1 & 29 May 2002 & 1710:38 & 15.4 & -8.8 & 12.5 \\
\hline 2 & 29 May 2002 & 1722:20 & 15.7 & -7.6 & 10.5 \\
\hline 3 & 29 May 2002 & 1738:18 & 16.2 & -2.8 & 5.2 \\
\hline 4 & 29 Мау 2002 & 1811:40 & 0.4 & -3.1 & 7.6 \\
\hline 5 & 29 May 2002 & 1836:03 & 0.5 & -7.9 & 13.1 \\
\hline 6 & 29 May 2002 & 1934:32 & 0.6 & -1.5 & 9.0 \\
\hline 7 & 29 May 2002 & 2006:59 & 16.3 & -0.8 & 9.0 \\
\hline 8 & 29 May 2002 & 2025:32 & 18.5 & -1.0 & 8.6 \\
\hline 9 & 9 Jun 2002 & 1255:19 & 0.6 & -5.0 & 7.7 \\
\hline
\end{tabular}

results in peak deviations of -1.2 and $0.8 \mathrm{~g} \mathrm{~kg}^{-1}$ or $-22 \%$ and $19 \%$, respectively, close to the transition zone. The mean bias between DLR DIAL and SRL data in the height interval of $1.5-3.4 \mathrm{~km}$ ASL is only $-0.19 \mathrm{~g} \mathrm{~kg}^{-1}$ or $-3.1 \%$ (DLR DIAL drier) in this case, while the mean RMS deviation is $0.39 \mathrm{~g} \mathrm{~kg}^{-1}$ or $7.6 \%$. The mean biases and RMS deviations for all comparison cases are listed also in Table 1.

For each comparison case, RMS deviation and bias between the two sensors have been computed in five height intervals of $500 \mathrm{~m}$ length from 1.3 to $3.8 \mathrm{~km}$. The results for these $500-\mathrm{m}$ height intervals and the whole 2.5-km interval of 1.3-3.8 km are shown in Fig. 3. With the exception of a few points, most bias values are within -0.5 and $0 \mathrm{~g} \mathrm{~kg}^{-1}$ or $-10 \%$ and $0 \%$ (DLR DIAL drier). Larger absolute bias values are found especially for the 500-m interval with lowest heights (1.3$1.8 \mathrm{~km}$ ASL), which is inside the boundary layer and contains also the highest absolute humidity. Nevertheless, the relative bias is also largest for this interval probably because of the large natural variability of the water vapor content in the planetary boundary layer. The biases for all comparison cases are within -2.0 to $+0.3 \mathrm{~g} \mathrm{~kg}^{-1}(-21 \%-7 \%)$, while the RMS deviations are $<2.1 \mathrm{~g} \mathrm{~kg}^{-1}$ or $21 \%$.

Table 2 and Fig. 4 show the bias and RMS deviation between SRL and DLR DIAL for five 500-m height intervals from 1.3 to $3.8 \mathrm{~km}$ and the whole interval between 1.3 and $3.8 \mathrm{~km}$. One can see a general decreasing trend of RMS deviation with height, which we believe is because of the larger variability of the water 

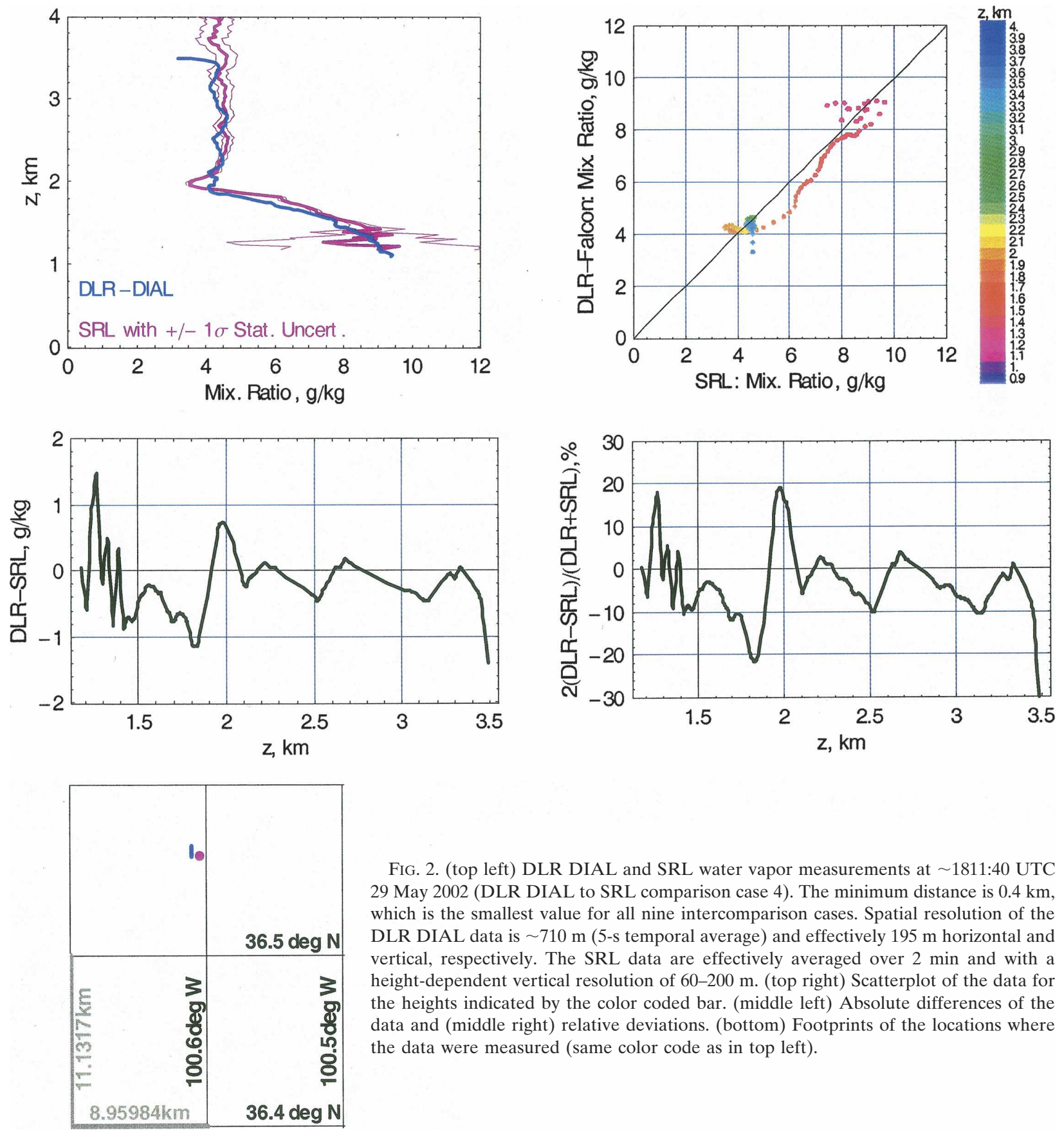

FIG. 2. (top left) DLR DIAL and SRL water vapor measurements at $\sim 1811: 40$ UTC 29 May 2002 (DLR DIAL to SRL comparison case 4). The minimum distance is $0.4 \mathrm{~km}$, which is the smallest value for all nine intercomparison cases. Spatial resolution of the DLR DIAL data is $\sim 710 \mathrm{~m}$ (5-s temporal average) and effectively $195 \mathrm{~m}$ horizontal and vertical, respectively. The SRL data are effectively averaged over $2 \mathrm{~min}$ and with a height-dependent vertical resolution of 60-200 m. (top right) Scatterplot of the data for the heights indicated by the color coded bar. (middle left) Absolute differences of the data and (middle right) relative deviations. (bottom) Footprints of the locations where the data were measured (same color code as in top left).

vapor content in lower heights for the comparisons possible between SRL and DLR DIAL.

There is no apparent dependency of the bias and RMS deviation on spatial distance of the measurement locations (see Table 1 and Fig. 5) here within the comparison cases selected with a $20-\mathrm{km}$ minimum distance: Small and large deviations between the SRL and DLR DIAL data are found for both large and small dis- tances. We believe that the reason for this counterintuitive result is that the number of possible intercomparisons is still too small to clearly display the expected dependency. The largest differences occur within the boundary layer and at the strong water vapor gradient at the boundary layer top as expected taking the temporal and spatial differences of the acquired data into account. 

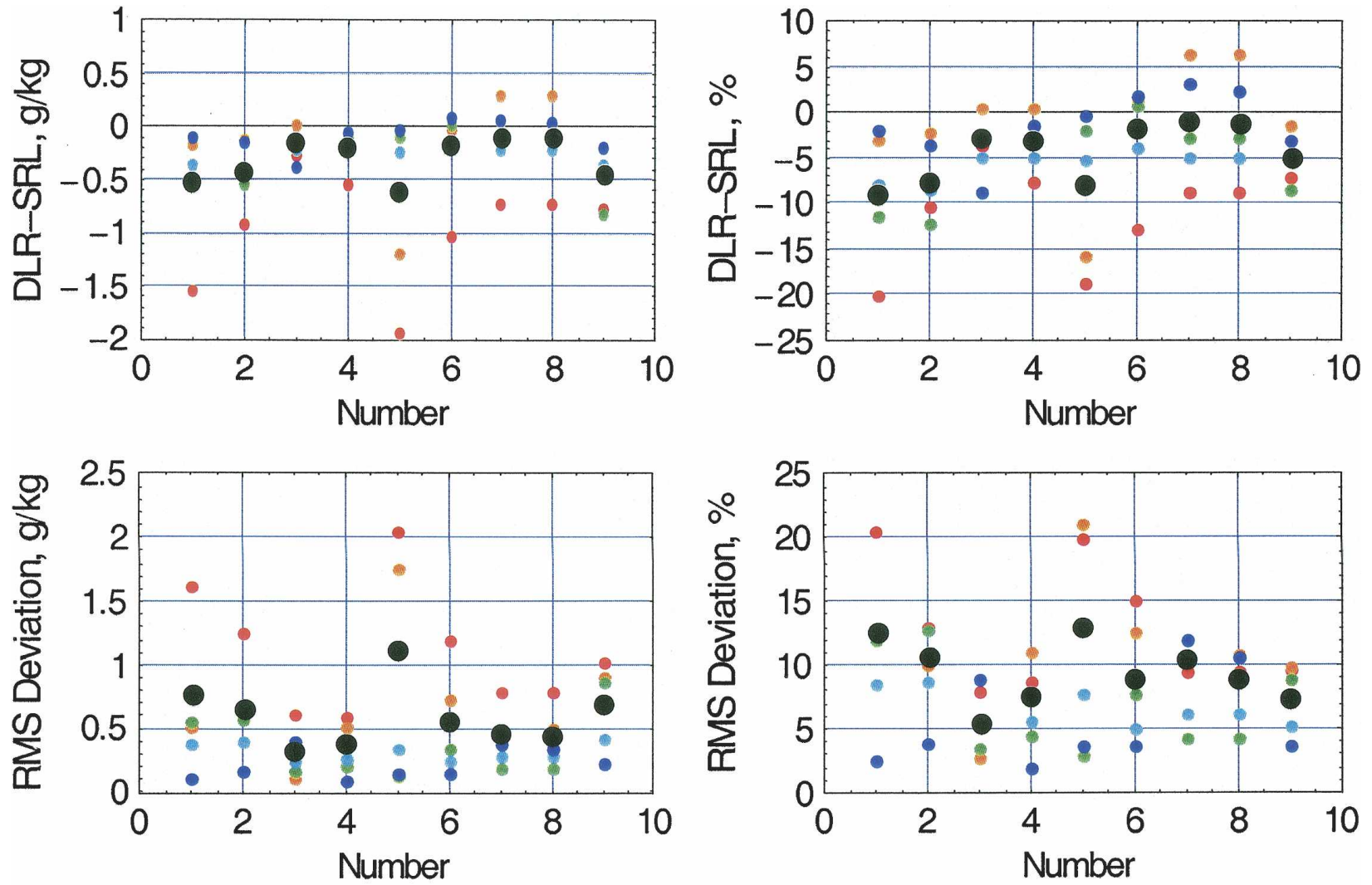

- $1.3-1.8 \mathrm{~km}$ ASL

- $1.8-2.3 \mathrm{~km} \mathrm{ASL}$

- $2.3-2.8 \mathrm{~km}$ ASL

- $2.8-3.3 \mathrm{~km}$ ASL

- $3.3-3.8 \mathrm{~km}$ ASL

- $1.3-3.8 \mathrm{~km}$ ASL

FIG. 3. Bias and RMS deviations for the nine possible intercomparisons between SRL and DLR DIAL. Different colors mark five consecutive height intervals of $500 \mathrm{~m}$ while black dots show bias and RMS deviations for the whole height interval between 1.3 and 3.8 $\mathrm{km}$ ASL (see the legend).

The overall mean results for the height interval between 1.3 and $3.8 \mathrm{~km}$ ASL are

$$
\begin{gathered}
\overline{\operatorname{Bias}}_{\text {DLR-SRL,absolute }}=(-0.30 \pm 0.25) \mathrm{g} \mathrm{kg}^{-1}, \\
\overline{\operatorname{Bias}}_{\text {DLR-SRL,relative }}=(-4.3 \pm 3.2) \%,
\end{gathered}
$$

$$
\begin{gathered}
\overline{\mathrm{RMS}}_{\text {absolute }}=(0.60 \pm 0.25) \mathrm{g} \mathrm{kg}^{-1}, \text { and } \\
\overline{\mathrm{RMS}}_{\text {relative }}=(9.2 \pm 2.5) \% .
\end{gathered}
$$

The agreement of the DLR DIAL and SRL data is very good taking the different measurement locations and

TABLE 2. Mean differences between SRL and DLR DIAL humidity data for the nine profiles, which were compared, with $1 \sigma$ standard

\begin{tabular}{|c|c|c|c|c|c|c|}
\hline $\begin{array}{l}\text { Height interval } \\
\text { (km ASL) }\end{array}$ & $\operatorname{Bias}\left(\mathrm{g} \mathrm{kg}^{-1}\right)$ & Bias (\%) & $\operatorname{RMS}\left(\mathrm{g} \mathrm{kg}^{-1}\right)$ & RMS (\%) & $\Delta q_{\mathrm{SRL}}\left(\mathrm{g} \mathrm{kg}^{-1}\right)$ & $\Delta q_{\mathrm{SRL}}(\%)$ \\
\hline $1.3-1.8$ & $-0.94 \pm 0.51$ & $-11.0 \pm 5.4$ & $1.10 \pm 0.49$ & $12.6 \pm 4.8$ & 0.4 & 5 \\
\hline $1.8-2.3$ & $-0.13 \pm 0.44$ & $-0.9 \pm 6.6$ & $0.65 \pm 0.47$ & $11.2 \pm 4.7$ & 0.1 & 3 \\
\hline $2.3-2.8$ & $-0.27 \pm 0.28$ & $-4.9 \pm 4.6$ & $0.35 \pm 0.25$ & $6.7 \pm 3.7$ & 0.1 & 3 \\
\hline $2.8-3.3$ & $-0.27 \pm 0.08$ & $-5.7 \pm 1.5$ & $0.31 \pm 0.07$ & $6.5 \pm 1.5$ & 0.2 & 4 \\
\hline $3.3-3.8$ & $-0.09 \pm 0.14$ & $-1.4 \pm 3.6$ & $0.22 \pm 0.12$ & $5.6 \pm 3.8$ & 0.3 & 6 \\
\hline $1.3-3.8$ & $-0.30 \pm 0.25$ & $-4.3 \pm 3.2$ & $0.60 \pm 0.25$ & $9.2 \pm 2.5$ & 0.2 & 3 \\
\hline
\end{tabular}
deviations; typical statistical uncertainties of the SRL data $\Delta q_{\mathrm{SRL}}$ (intercomparison number 1 at 1710:54 UTC 29 May 2002) are given as example. The statistical uncertainties of the SRL data with 2-min effective resolution are small for all the comparisons which were possible between SRL and DLR DIAL. 

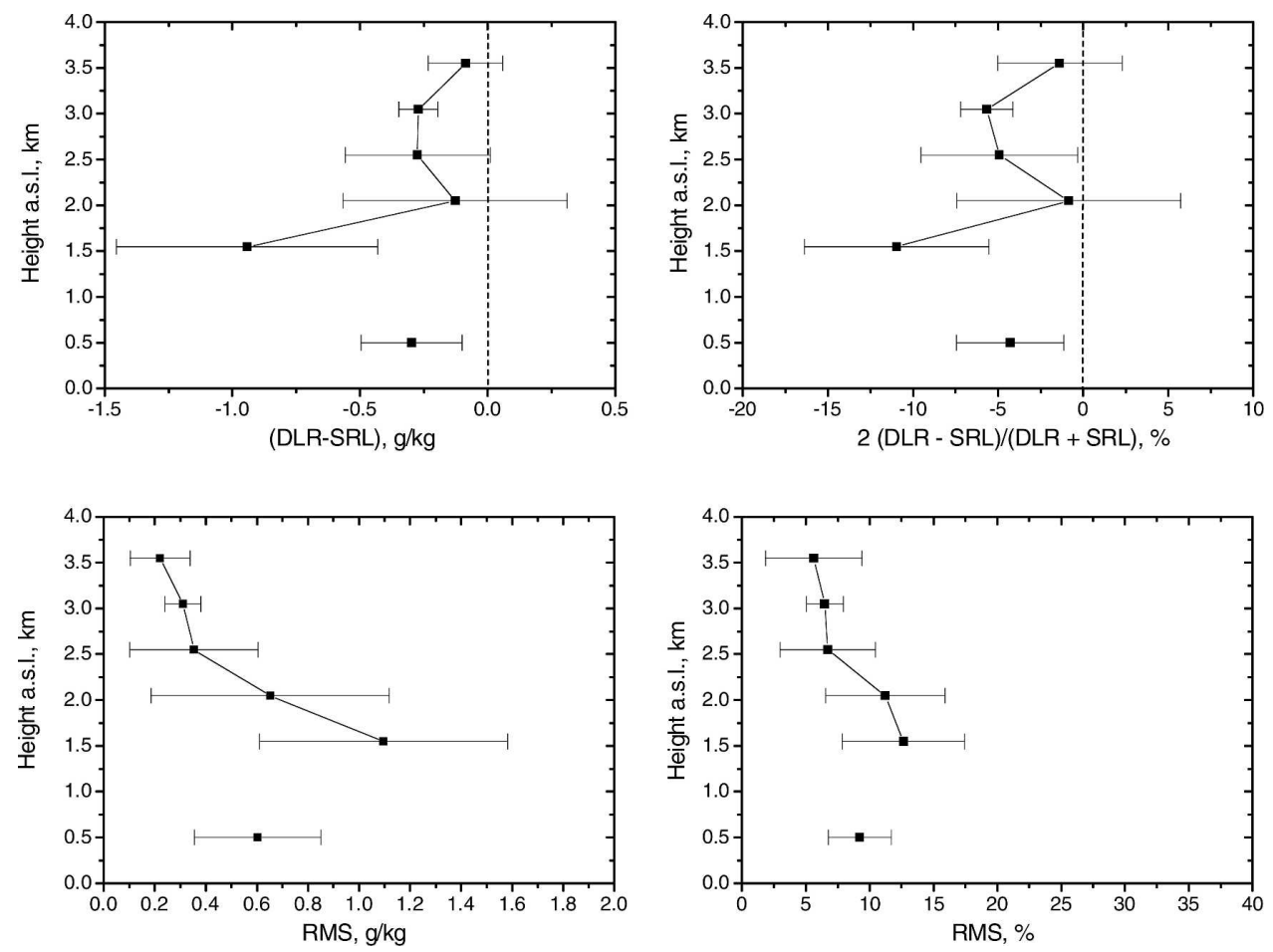

FIG. 4. Mean results for 500-m height intervals and nine intercomparisons of SRL and DLR DIAL data. Error bars show the $\pm 1 \sigma$ standard deviation of the nine comparison cases. The data points plotted at $0.5-\mathrm{km}$ height ASL show the mean values for the height interval of $1.3-3.8 \mathrm{~km}$ ASL. The ground level height is $862 \mathrm{~m}$ ASL at the Homestead Profiling Site where the SRL was located during IHOP_2002. (Same data as listed in Table 2.)

periods into account and considering that the cross section employed by the DLR-DIAL has been taken from the HITRAN_2001 database. It is known that the parameters of weak water vapor absorption lines like the one used by the DLR DIAL during IHOP_2002 listed in HITRAN_2001 are accurate only within several percent.

\section{Intercomparisons of SRL and LASE}

Comparisons between SRL and LASE water vapor data are possible with data of three days: 30 May, 3 June, and 9 June 2002. Intercomparison cases of 14 June were discarded because of an operational problem with LASE that precluded an independent comparison with SRL. For this reason, the total number of possible comparisons between SRL and LASE is 10 (Table 3). Comparisons are based on 10-min averages of SRL and 1-min averages for LASE. We decided to use a larger temporal averaging window for the SRL to LASE comparisons than for the SRL to DLR-DIAL comparisons because the DC-8 carrying LASE flew faster and at higher altitudes than the DLR-Falcon. Based on 10-min averaging, the statistical uncertainty of all the SRL data used here is smaller than $10 \%$ for all heights below 2.8 to $4.3 \mathrm{~km}$, with exact height different for each profile. During nighttime, the $10 \%$ uncertainty level typically rises to above $8 \mathrm{~km}$.

As an example, the comparison with closest minimum distance between SRL and LASE (at 2030 UTC 3 June 2003) is shown in Fig. 6. To compute deviations, we decided arbitrarily to interpolate the SRL data to LASE data heights. The largest differences between the two sensors are found at the boundary layer transition zone between 2.2 and $3.0 \mathrm{~km}$ ASL where the gradient is smoother in the LASE data. Here the LASE data are up to $0.8 \mathrm{~g} \mathrm{~kg}^{-1}$ or $28 \%$ moister near $2.8 \mathrm{~km}$. Correspondingly, differences of $-0.5 \mathrm{~g} \mathrm{~kg}^{-1}$ or $-8 \%$ (LASE drier) are found at 2.3-km height. This is most probably due to the averaging of the LASE data over a larger horizontal path and therefore stronger smoothing over natural boundary layer top variations. This results in a steeper gradient of the SRL water vapor data at the planetary boundary layer top. Larger deviations of $0.6 \mathrm{~g} \mathrm{~kg}^{-1}$ or $26 \%$ (LASE moister) are also found near $3.8-\mathrm{km}$ height where the statistical uncertainty of the SRL data becomes larger with about $10 \%$. Otherwise, the differences are smaller than $10 \%$ or 

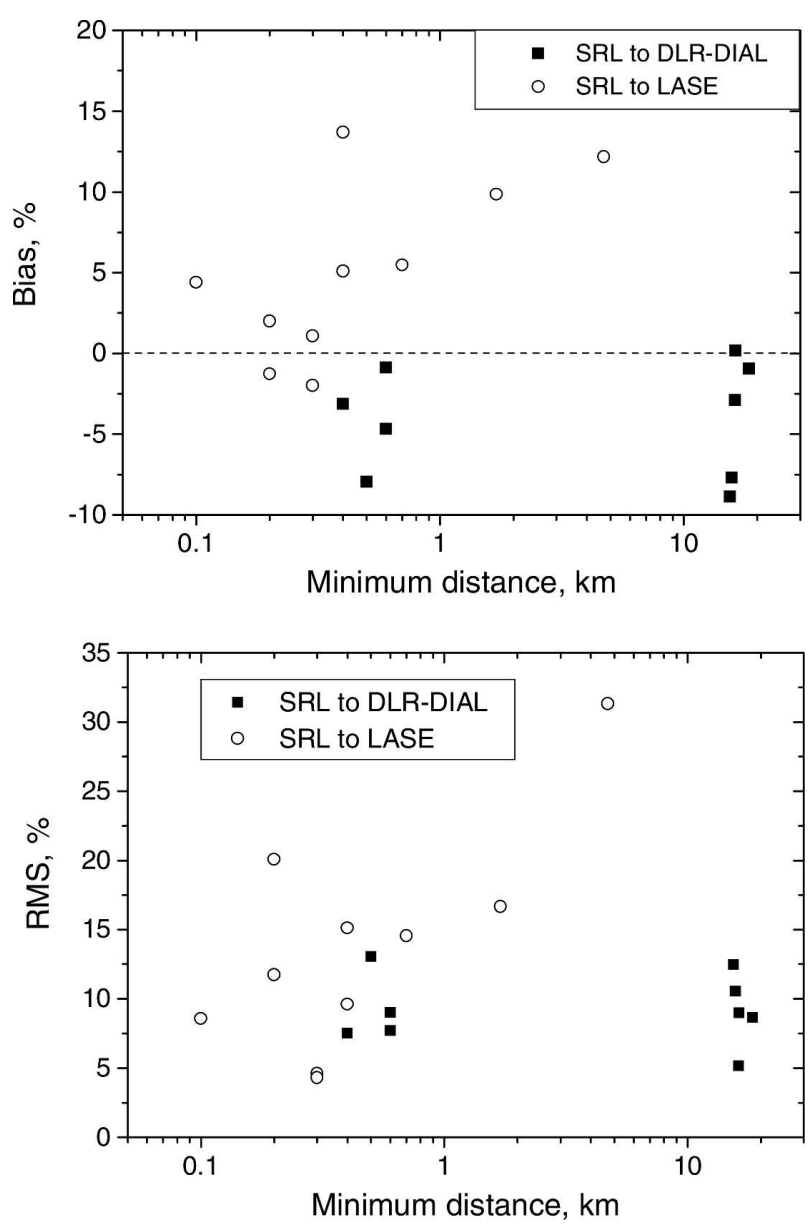

FIG. 5. Relative bias and RMS deviation for all intercomparisons with SRL vs minimum distance between SRL and the footprint of DLR DIAL and LASE, respectively.

$0.5 \mathrm{~g} \mathrm{~kg}^{-1}$ for all heights. The mean bias in the height interval of $1.3-1.8 \mathrm{~km}$ ASL is very small and only $-0.5 \%$ or $-0.04 \mathrm{~g} \mathrm{~kg}^{-1}$ in this case.

Figure 7 shows the bias and RMS deviation between

TABLE 3. Same as Table 1, but for SRL and LASE.

\begin{tabular}{|c|c|c|c|c|c|}
\hline No. & Date & $\begin{array}{l}\text { Time } \\
\text { (UTC) }\end{array}$ & $\begin{array}{c}\text { Min } \\
\text { distance } \\
(\mathrm{km})\end{array}$ & $\begin{array}{c}\text { Mean bias } \\
\text { LASE SRL } \\
1.3-3.8 \mathrm{~km} \\
(\%)\end{array}$ & $\begin{array}{c}\text { Mean RMS } \\
\text { deviation, } \\
1.3-3.8 \mathrm{~km} \\
(\%)\end{array}$ \\
\hline 1 & 30 May & 1828:06 & 4.7 & 12.2 & 31.3 \\
\hline 2 & 30 May & 1944:41 & 0.4 & 5.1 & 9.6 \\
\hline 3 & 30 May & 2034:58 & 1.7 & 9.9 & 16.7 \\
\hline 4 & 30 May & 2149:11 & 0.4 & 13.7 & 15.1 \\
\hline 5 & 3 Jun & 1929:46 & 0.7 & 5.5 & 14.5 \\
\hline 6 & 3 Jun & 2030:09 & 0.1 & 4.4 & 8.6 \\
\hline 7 & 3 Jun & 2132:15 & 0.3 & 1.1 & 4.6 \\
\hline 8 & 9 Jun & 1806:50 & 0.3 & -2.0 & 4.3 \\
\hline 9 & 9 Jun & 1917:03 & 0.2 & 2.0 & 11.7 \\
\hline 10 & 9 Jun & 2031:03 & 0.2 & 1.3 & 20.1 \\
\hline
\end{tabular}

SRL and LASE for five 500-m height intervals from 1.3 to $3.8 \mathrm{~km}$. With the exception of a few points, most bias values are within -0.6 and $1.0 \mathrm{~g} \mathrm{~kg}^{-1}$ or $-10 \%$ and $15 \%$. Different to what was found for the comparisons between SRL and DLR DIAL, we see here relatively small differences for the 500-m interval with lowest heights (1.3-1.8 km ASL), while large relative bias values are especially found for higher altitudes where the absolute humidity is low. The biases for all comparison cases are within -1.4 to $+1.6 \mathrm{~g} \mathrm{~kg}^{-1}$ ( $-11 \%$ to $\left.10 \%\right)$, when we discard the especially large relative deviations found for the highest two intervals in some of the cases. The RMS deviations are mostly $<1.5 \mathrm{~g} \mathrm{~kg}^{-1}$ or $20 \%$, again with a few exceptions especially for the highaltitude intervals.

The decrease of bias and RMS deviations with increasing height found for the DLR DIAL to SRL comparison cases are not seen here for the comparisons between SRL and LASE (Fig. 8 and Table 4). Looking at the mean values, one might think about an opposite trend, which, however, is statistically not significant because the standard deviations of the mean values are larger than the apparent trend of the mean values.

The overall mean results for the height interval between 1.3 and $3.8 \mathrm{~km}$ ASL are

$$
\begin{aligned}
\overline{\operatorname{Bias}}_{\text {LASE-SRL,absolute }} & =(0.16 \pm 0.31) \mathrm{g} \mathrm{kg}^{-1}, \\
\overline{\operatorname{Bias}}_{\text {LASE-SRL,relative }} & =(5.3 \pm 5.1) \%, \\
\overline{\mathrm{RMS}}_{\text {absolute }} & =(0.64 \pm 0.37) \mathrm{g} \mathrm{kg}^{-1}, \text { and } \\
\overline{\mathrm{RMS}}_{\text {relative }} & =(13.6 \pm 8.0) \% .
\end{aligned}
$$

Similar to the comparisons between the DLR DIAL and SRL, the largest deviations between the two instruments are typically found at the top of the boundary layer, which is characterized by large humidity gradients and large variations of the height of this gradient both in space and time so that sampling differences have significant effects.

As both the SRL and LASE data usually extend to greater altitudes than the DLR DIAL data (the DLRFalcon flew in $4-5 \mathrm{~km}$ ASL while the DC-8 carrying LASE flew in $8-10 \mathrm{~km} \mathrm{ASL}$ ), we also calculated the mean bias and RMS deviation between SRL and LASE in the altitude regions of 1.3-4.0, 1.3-5.0, 1.3-6.0, and $1.3-7.0 \mathrm{~km}$ ASL. The average RMS deviations between SRL and LASE are found to be $11.9 \%, 25.5 \%, 33.6 \%$, and $15.8 \%$ up to $4.0,5.0,6.0$, and $7.0 \mathrm{~km} \mathrm{ASL}$, while the biases are $3.1 \%, 9.4 \%, 8.6 \%$, and $20.2 \%$ for the same height intervals.

Figure 5 shows bias and RMS deviation versus mini- 

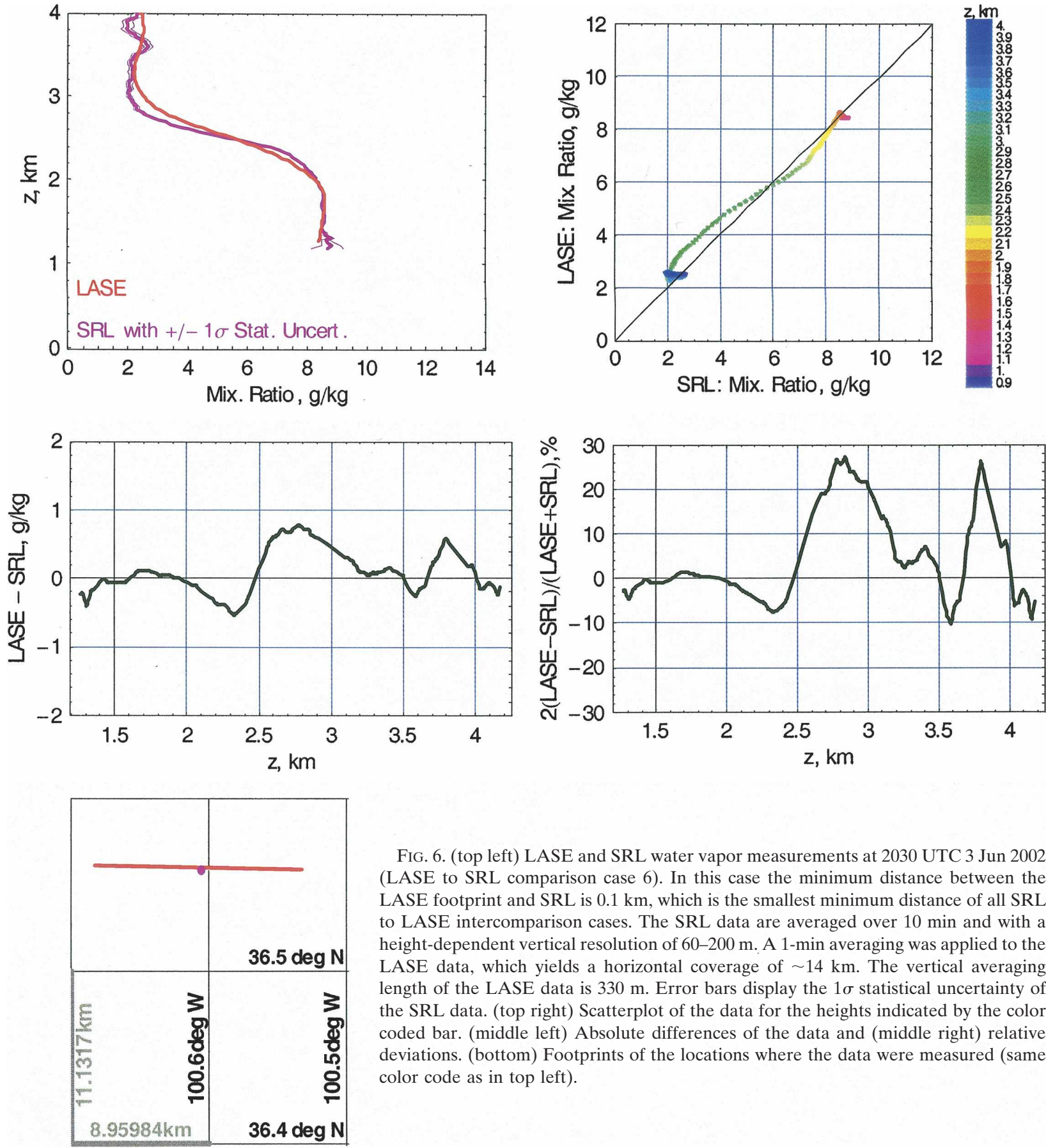

FIG. 6. (top left) LASE and SRL water vapor measurements at 2030 UTC 3 Jun 2002 (LASE to SRL comparison case 6). In this case the minimum distance between the LASE footprint and SRL is $0.1 \mathrm{~km}$, which is the smallest minimum distance of all SRL to LASE intercomparison cases. The SRL data are averaged over 10 min and with a height-dependent vertical resolution of 60-200 $\mathrm{m}$. A 1-min averaging was applied to the LASE data, which yields a horizontal coverage of $\sim 14 \mathrm{~km}$. The vertical averaging length of the LASE data is $330 \mathrm{~m}$. Error bars display the $1 \sigma$ statistical uncertainty of the SRL data. (top right) Scatterplot of the data for the heights indicated by the color coded bar. (middle left) Absolute differences of the data and (middle right) relative deviations. (bottom) Footprints of the locations where the data were measured (same color code as in top left).

mum distance of the LASE footprint and the SRL site. There is some indication for a dependency of the mean differences on the minimum distance of the sensors, denoted with $x$ in the following. We found the following approximations for $4.7 \mathrm{~km}>x>0.1 \mathrm{~km}$ :

$$
\begin{aligned}
\overline{\mathrm{RMS}}_{\text {relative }} & =[17.7+11.6 \times \log (x / \mathrm{km})] \%, \\
R & =0.71, \text { and }
\end{aligned}
$$

$$
\begin{aligned}
\overline{\operatorname{Bias}}_{\text {LASE-SRL,relative }} & =[7.5+7.1 \times \log (x / \mathrm{km})] \%, \\
R & =0.64,
\end{aligned}
$$

where $R$ is the correlation coefficient. But because $R$ is $\ll 1$, the correlation is not very high. Again, we believe that this is because the number of possible intercomparisons is still too small to display this expected trend more clearly. 

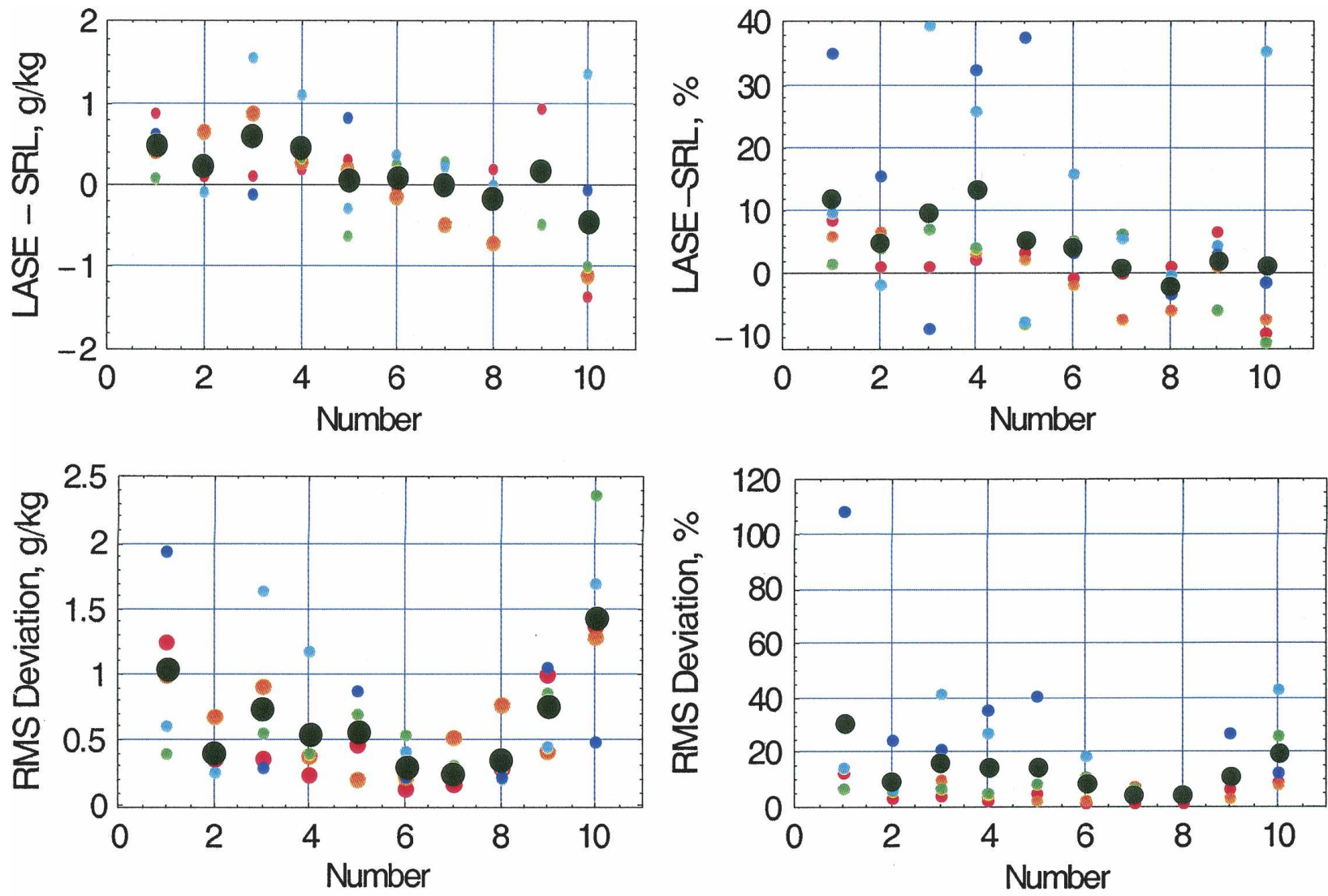

- $1.3-1.8 \mathrm{~km}$ ASL

- $1.8-2.3 \mathrm{~km}$ ASL

- $2.3-2.8 \mathrm{~km}$ ASL

- $2.8-3.3 \mathrm{~km}$ ASL

- $3.3-3.8 \mathrm{~km} \mathrm{ASL}$

- $1.3-3.8 \mathrm{~km}$ ASL

FIG. 7. Bias and RMS deviations for the 10 possible intercomparisons between SRL and LASE. Different colors mark five consecutive height intervals of $500 \mathrm{~m}$ (see legend, same as in Fig. 3), while black dots show bias and RMS deviations for the whole height interval between 1.3 and $3.8 \mathrm{~km}$ ASL. For intercomparison number 7 (2132:15 UTC 3 Jun 2002), there are no data available for the interval 3.3-3.8 km; therefore, the mean averages were calculated for the interval of 1.3-3.3 km ASL for this intercomparison case.

\section{Intercomparisons of the scanning Raman lidar and reference radiosondes}

In addition to lidar-to-lidar intercomparisons, we also investigated comparisons between SRL and chilled-mirror hygrometer radiosonde data. There were nine launches of Snow White (SW) from the Homestead Profiling Site during IHOP_2002 (Wang et al. 2003), four of which were during periods where SRL data are available. Comparisons between radiosondes and ground-based Raman lidar have been performed frequently before (e.g., Nagel et al. 2001). Chilledmirror hygrometers are of special interest in this context because their humidity data are more precise than the data of other radiosonde sensors and do not require extensive calibration correction tables like other radiosonde humidity sensors.

Unfortunately, the launches of SW sondes and the flight tracks and operation of the airborne DIAL systems do not match during IHOP_2002. We analyzed all the flight tracks and launches and found that there are no intercomparisons possible between either LASE or DLR DIAL and SW sondes using the same selection criterion of a $20-\mathrm{km}$ distance like for the lidar-to-lidar intercomparisons.

The main components of the National Center for Atmospheric Research (NCAR) reference radiosonde are a Swiss SRS C34 radiosonde manufactured by Meteola- 

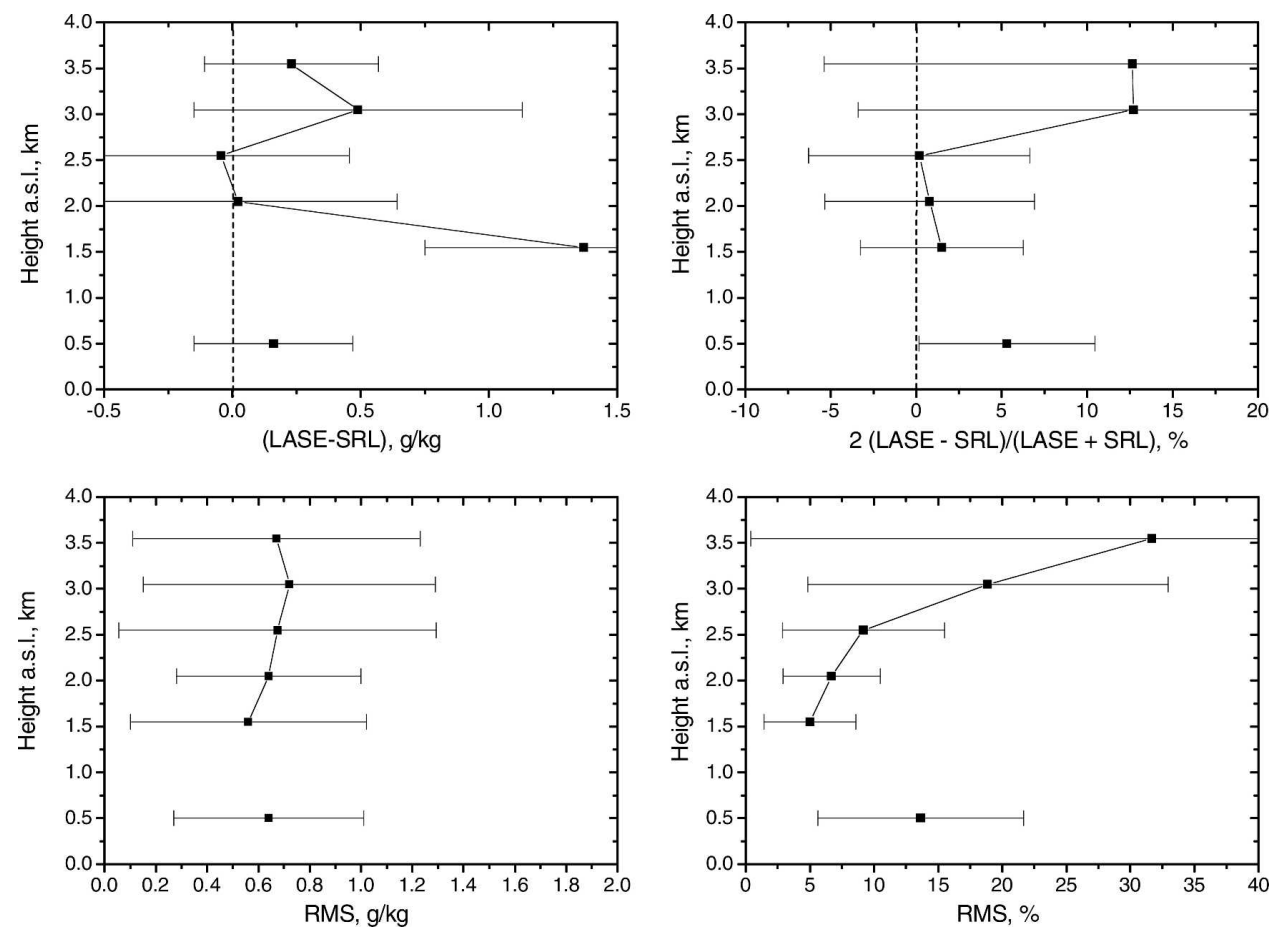

FIG. 8. Mean result for 500-m intervals and 10 intercomparisons of SRL and LASE. Error bars show the $\pm 1 \sigma$ standard deviation of the 10 comparison cases. The data points plotted at $0.5-\mathrm{km}$ height ASL show the mean values for the height interval of 1.3-3.8 km ASL. The ground level height is $862 \mathrm{~m}$ ASL at the Homestead Profiling Site where the SRL was located during IHOP_2002 (same data as in Table 4).

bor AG, Switzerland, to measure temperature, humidity, and pressure; a Garmin GPS receiver to measure wind; a dropsonde $400-\mathrm{MHz}$ telemetry transmitter to transmit data from multiple sensors to the ground; and a wood or plastic boom for carrying the reference radiosonde at one end and another radiosonde at the other end. The C34 consists of an SW chilled-mirror dewpoint hygrometer and a carbon hygristor manufactured by Sippican, Inc., for humidity measurements, a small copper-constantan thermocouple (0.05-mm diameter) for temperature and a full range hypsometer for pressure.

The SW hygrometer is used as the reference humidity sensor and is based on the physically well-known chilled-mirror technique, in which a layer of condensate on a mirror is maintained at a constant reflectivity by continuously adjusting the temperature of the mirror, so that condensate neither grows nor shrinks. The mirror temperature is equivalent to the dewpoint temperature of the air. The accuracy of the mirror temperature measurement is better than $0.1 \mathrm{~K}$, corresponding to $0.25 \%$ in terms of relative humidity. The SW response time is negligible at $+20^{\circ} \mathrm{C}, 10 \mathrm{~s}$ at $-30^{\circ} \mathrm{C}$, and $80 \mathrm{~s}$ at $-60^{\circ} \mathrm{C}$.

There are data for four comparisons between SRL and the NCAR reference sonde available on 28 May and 9, 18, and 20 June 2002. To reduce the effects of temporal and spatial inhomogeneities of the water vapor field, SRL data with a 10-min average were used here to derive bias and RMS deviations. Water vapor mixing ratios for the reference sonde have been calculated using pressure information from the Vaisala RS80 or VIZ sonde flown simultaneously on the same balloon since the pressure data from the reference sonde itself was found to be not reliable. Figure 9 shows the mean profile of SRL and the reference sonde data of the four possible comparisons as well as the absolute and relative bias between SRL and the reference sonde. The absolute differences are mostly smaller than \pm 0.5 $\mathrm{g} \mathrm{kg}^{-1}$ between 2 and $5.5 \mathrm{~km} \mathrm{ASL}$ and within the interval of -2 to $0.8 \mathrm{~g} \mathrm{~kg}^{-1}$ up to $8 \mathrm{~km} \mathrm{ASL}$. The relative differences are mostly smaller than $\pm 10 \%$ up to $4 \mathrm{~km}$ and higher above where also the absolute humidity becomes smaller. In general, larger relative differences at higher altitudes are caused by the increasing distance between the drifting sondes and the vertical column, which is sampled by the lidar.

Again, for each of the four cases, RMS deviation and bias between the two sensors have been computed using Eqs. (1)-(5) in 500-m intervals between 1.3 and 3.8 

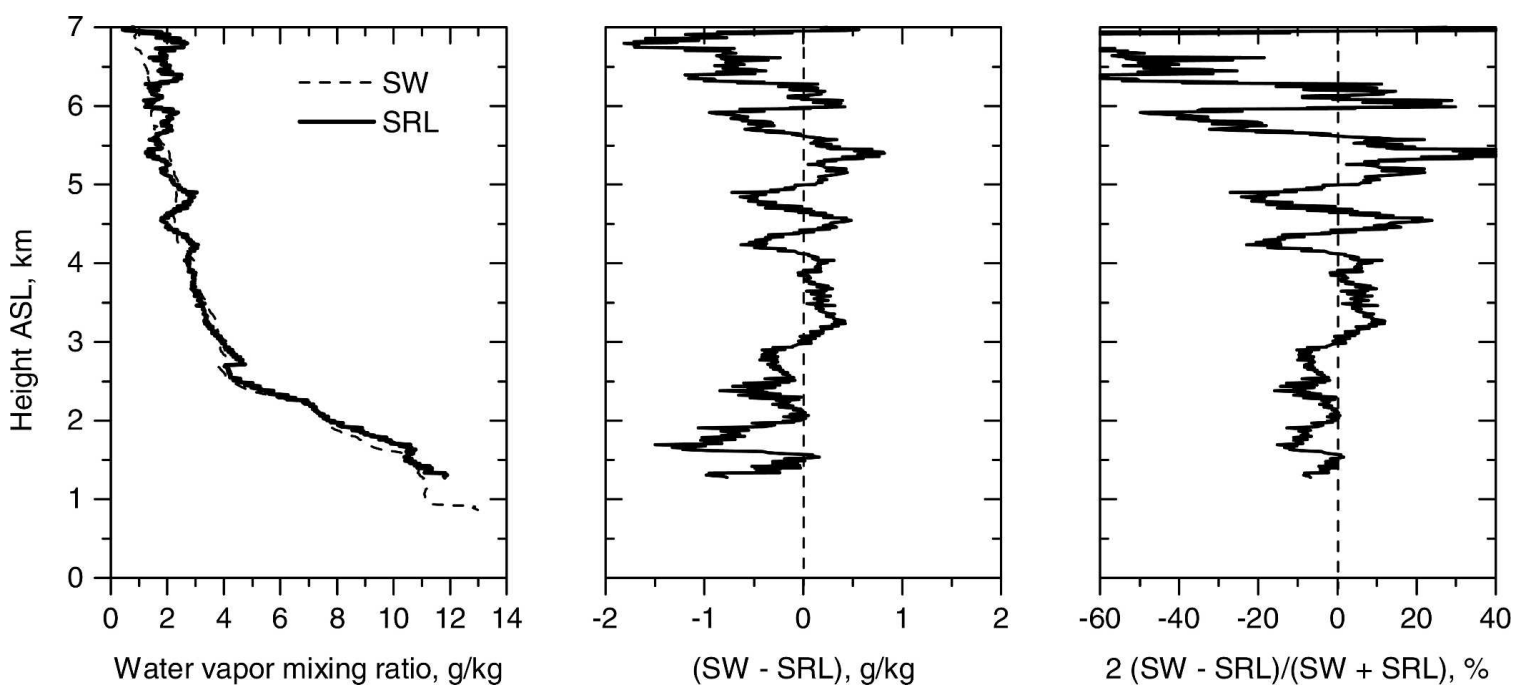

FIG. 9. Mean profiles of (left) SRL and SW humidity data, (middle) absolute, and (right) relative bias between the data. The ground level height is $862 \mathrm{~m}$ ASL at the Homestead Profiling Site where the SRL was located during IHOP_2002 and the SW sondes were launched. Steps in the data are due to data gaps in either one of the comparison cases.

km above sea level (Fig. 10; Table 5). For the profiles with high vertical resolution shown in Fig. 9, the effects of sampling errors due to the drift of the radiosondes are of course larger than for comparisons of mean values for $500-\mathrm{m}$ intervals. It is found that absolute bias and RMS deviation decrease with height due to decreasing absolute humidity in the atmosphere. In case of the bias, this trend, however, is statistically not very significant because of the large differences between the four comparison cases. The relative bias for all 500-m intervals is between $-5.4 \% \pm 8.9 \%$ and $-0.7 \% \pm$ $10.7 \%$ while the RMS deviations are between $6.2 \% \pm$ $4.0 \%$ and $12.3 \% \pm 13.0 \%$. For the whole $2.5-\mathrm{km}$ interval between 1.3 and $3.8 \mathrm{~km}$ ASL, we found

$$
\begin{aligned}
\overline{\mathrm{Bias}}_{\text {SW-SRL,absolute }} & =(-0.27 \pm 0.38) \mathrm{g} \mathrm{kg}^{-1}, \\
\overline{\mathrm{Bias}}_{\text {SW-SRL,relative }} & =(-3.2 \pm 4.5) \%, \\
\overline{\mathrm{RMS}}_{\text {absolute }} & =(0.78 \pm 0.29) \mathrm{g} \mathrm{kg}^{-1}, \quad \text { and } \\
\overline{\mathrm{RMS}}_{\text {relative }} & =(11.8 \pm 5.2) \% .
\end{aligned}
$$

In addition to these intervals, we calculated also the deviations for higher altitudes. The average RMS deviation between SRL and SW is $11.9 \%$ up to $4.0 \mathrm{~km}$, $15.9 \%$ up to $6.0 \mathrm{~km}$, and $34.8 \%$ up to $8.0 \mathrm{~km}$, while the average bias between SRL and the SW sondes is $-3.0 \%$ up to $4.0 \mathrm{~km},-3.7 \%$ up to $6.0 \mathrm{~km}$, and $-7.7 \%$ up to $8.0 \mathrm{~km}$.

\section{Overall results}

The most appropriate measure of deviations between water vapor lidars is the relative bias because most po- tential errors in the system calibrations for both Raman lidar and DIAL approximately scale with the amount of water vapor (water vapor mixing ratio and water vapor number concentration for Raman lidar and DIAL, respectively).

To derive the overall bias values for the lidars that we denote with $\overline{\operatorname{Bias}}_{\text {DLR,relative }}, \overline{\operatorname{Bias}}_{\text {LASE,relative, and }}$ $\overline{\operatorname{Bias}}_{\text {SRL,relative, }}$, we write

$$
\begin{aligned}
\overline{\operatorname{Bias}}_{\text {LASE-SRL,relative }}= & \overline{\operatorname{Bias}}_{\text {LASE,relative }} \\
& -\overline{\operatorname{Bias}}_{\text {SRL,relative }}
\end{aligned}
$$

and

$$
\overline{\operatorname{Bias}}_{\text {DLR-SRL,relative }}=\overline{\operatorname{Bias}}_{\text {DLR,relative }}-\overline{\text { Bias }}_{\text {SRL,relative }} \text {. }
$$

Putting equal weight on the data reliability of each instrument, we set the sum of the bias values to zero:

$$
\overline{\operatorname{Bias}}_{\text {DLR,relative }}+\overline{\operatorname{Bias}}_{\text {LASE,relative }}+\overline{\operatorname{Bias}}_{\mathrm{SRL}, \text { relative }}=0 \text {. }
$$

With the results discussed in sections 5 and 6 for the height interval of $1.3-3.8 \mathrm{~km}$ ASL, we get

$$
\begin{aligned}
\overline{\operatorname{Bias}}_{\text {DLR,relative }} & =-4.6 \%, \\
\overline{\operatorname{Bias}}_{\text {SRL,relative }} & =-0.4 \%, \text { and } \\
\overline{\operatorname{Bias}}_{\text {LASE,relative }} & =5.0 \% .
\end{aligned}
$$

[Rounding the values quoted above results in differences of up to $0.1 \%$, when these data are inserted in Eqs. (7) and (8) and the results are compared with the 

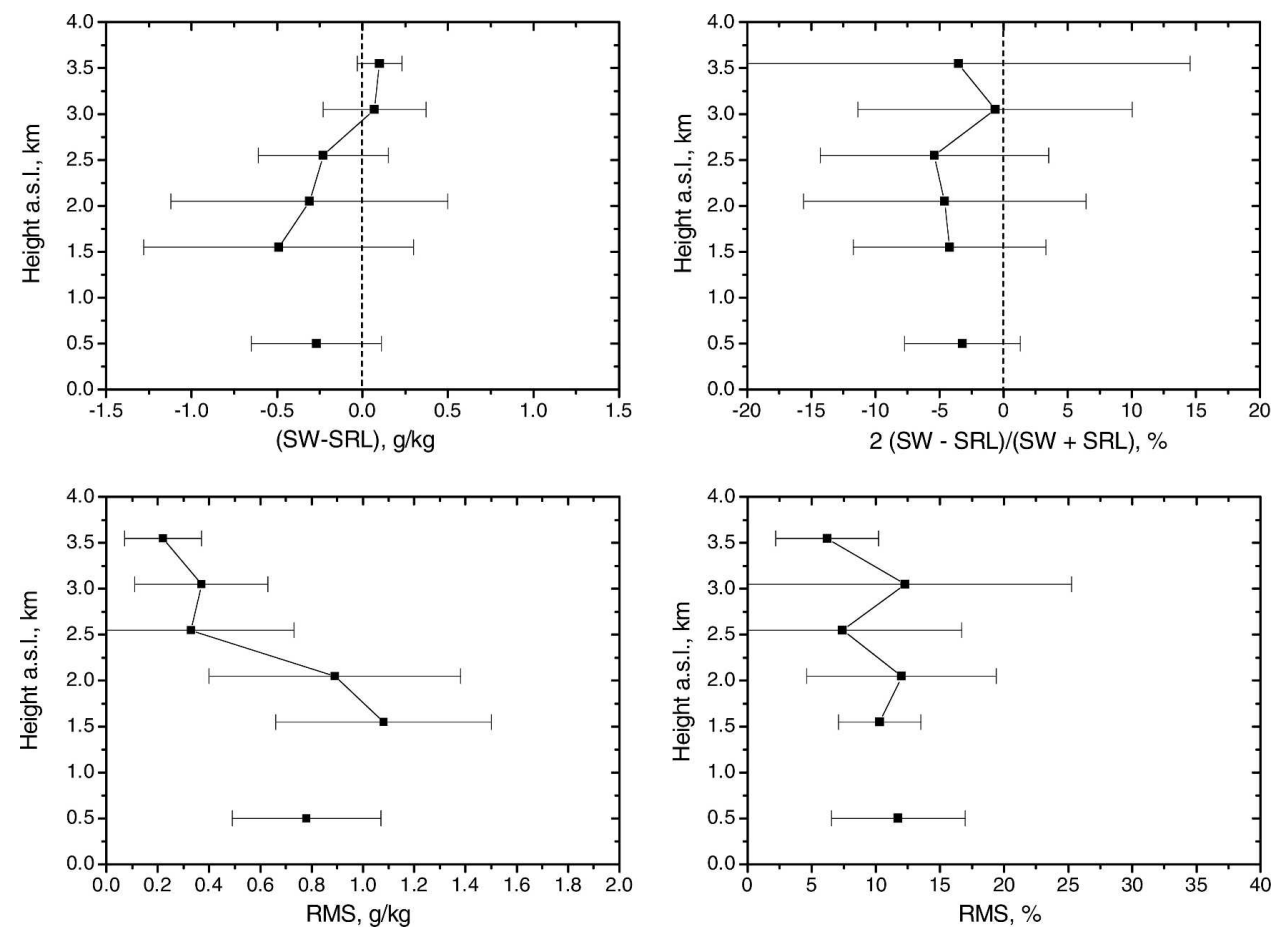

FIG. 10. Mean result for 500-m intervals and four intercomparisons of SRL and SW sondes. Error bars show the $\pm 1 \sigma$ standard deviation of the four comparison cases. The data points plotted at $0.5-\mathrm{km}$ height ASL show the mean values for the height interval of 1.3-3.8 km ASL. The ground level height is $862 \mathrm{~m}$ ASL at the Homestead Profiling Site where the SRL was located during IHOP_2002 (same data as in Table 5).

values quoted in sections 5 and 6.] Figure 11 shows the overall results of the intercomparisons between SRL and LASE and between SRL and DLR DIAL. In addition, the results for the comparisons between SW and LASE are depicted.

\section{Summary and conclusions}

We compared humidity measurements performed by two airborne DIAL systems, LASE and DLR DIAL, and one ground-based Raman lidar system, namely, SRL, during IHOP_2002. For these three instruments the numbers of possible intercomparisons with the IHOP_2002 dataset are 10 and 9, respectively. The number of airborne to ground-based intercomparisons with the other two lidars operated during IHOP_2002, are considered to be too small to derive conclusions on system performances and are not discussed here. In addition to lidar-to-lidar intercomparisons, we also investigated comparisons between SRL and chilledmirror hygrometer radiosonde data. There were nine launches of SW radiosondes from the Homestead Profiling Site during IHOP_2002, four of which were during periods when SRL data were available.

TABLE 4. Mean differences between SRL and LASE humidity data for the 10 profiles, which were compared, with standard deviation of this mean; typical statistical uncertainties $\Delta q_{\mathrm{SRL}}$ of the SRL data used for the comparisons between SRL and LASE are given as example (10-min average, no further vertical averaging; data of intercomparison 6, see Fig. 6).

\begin{tabular}{|c|c|c|c|c|c|c|}
\hline $\begin{array}{c}\text { Height } \\
\text { interval } \\
(\mathrm{km} \mathrm{ASL})\end{array}$ & Bias $\left(\mathrm{g} \mathrm{kg}^{-1}\right)$ & Bias (\%) & RMS $\left(\mathrm{g} \mathrm{kg}^{-1}\right)$ & RMS (\%) & $\begin{array}{c}\Delta q_{\mathrm{SRL}} \\
\left(\mathrm{g} \mathrm{kg}^{-1}\right)\end{array}$ & $\begin{array}{c}\Delta q_{\mathrm{SRL}} \\
(\%)\end{array}$ \\
\hline $1.3-1.8$ & $1.37 \pm 0.62$ & $1.5 \pm 4.8$ & $0.56 \pm 0.46$ & $5.0 \pm 3.6$ & 0.03 & 0.3 \\
\hline $1.8-2.3$ & $0.02 \pm 0.62$ & $0.8 \pm 6.1$ & $0.64 \pm 0.36$ & $6.7 \pm 3.8$ & 0.03 & 0.4 \\
\hline $2.3-2.8$ & $-0.05 \pm 0.50$ & $0.2 \pm 6.5$ & $0.67 \pm 0.62$ & $9.2 \pm 6.3$ & 0.06 & 1.5 \\
\hline $2.8-3.3$ & $0.49 \pm 0.64$ & $12.7 \pm 16.1$ & $0.72 \pm 0.57$ & $18.9 \pm 14.0$ & 0.09 & 4.5 \\
\hline $3.3-3.8$ & $0.23 \pm 0.34$ & $12.6 \pm 18.0$ & $0.67 \pm 0.56$ & $31.7 \pm 31.3$ & 0.15 & 5.7 \\
\hline $1.3-3.8$ & $0.16 \pm 0.31$ & $5.3 \pm 5.1$ & $0.64 \pm 0.37$ & $13.7 \pm 8.0$ & 0.07 & 2.5 \\
\hline
\end{tabular}


TABLE 5. Mean differences between SRL and SW humidity data for the four profiles that were compared with $1 \sigma$ standard deviation of the four comparison cases.

\begin{tabular}{ccccc}
\hline $\begin{array}{c}\text { Height } \\
\text { interval } \\
(\mathrm{km} \mathrm{ASL})\end{array}$ & $\begin{array}{c}\text { Bias } \\
\left(\mathrm{g} \mathrm{kg}^{-1}\right)\end{array}$ & \multicolumn{1}{c}{ Bias (\%) } & $\begin{array}{c}\text { RMS } \\
\left(\mathrm{g} \mathrm{kg}^{-1}\right)\end{array}$ & RMS (\%) \\
\hline $1.3-1.8$ & $-0.49 \pm 0.79$ & $-4.2 \pm 7.5$ & $1.08 \pm 0.42$ & $10.3 \pm 3.2$ \\
$1.8-2.3$ & $-0.31 \pm 0.81$ & $-4.6 \pm 11.0$ & $0.89 \pm 0.49$ & $12.0 \pm 7.4$ \\
$2.3-2.8$ & $-0.23 \pm 0.38$ & $-5.4 \pm 8.9$ & $0.33 \pm 0.40$ & $7.4 \pm 9.3$ \\
$2.8-3.3$ & $0.07 \pm 0.30$ & $-0.7 \pm 10.7$ & $0.37 \pm 0.26$ & $12.3 \pm 13.0$ \\
$3.3-3.8$ & $0.10 \pm 0.13$ & $-3.5 \pm 18.0$ & $0.22 \pm 0.15$ & $6.2 \pm 4.0$ \\
$1.3-3.8$ & $-0.27 \pm 0.38$ & $-3.2 \pm 4.5$ & $0.78 \pm 0.29$ & $11.8 \pm 5.2$ \\
\hline
\end{tabular}

The SRL data were precisely calibrated for IHOP_2002 using a single, height-independent calibration constant determined from the updated processing of the SuomiNet GPS data. Temperature and overlap effects have been corrected. For the comparisons between SRL and SW radiosondes, we found for the 2.5$\mathrm{km}$ interval between 1.3 and $3.8 \mathrm{~km}$ ASL

$$
\begin{aligned}
\overline{\operatorname{Bias}}_{\mathrm{SW}-\mathrm{SRL}, \text { absolute }} & =(-0.27 \pm 0.38) \mathrm{g} \mathrm{kg}^{-1}, \\
\overline{\mathrm{Bias}}_{\mathrm{SW}-\mathrm{SRL}, \text { relative }} & =(-3.2 \pm 4.5) \%, \\
\overline{\mathrm{RMS}}_{\text {absolute }} & =(0.78 \pm 0.29) \mathrm{g} \mathrm{kg}^{-1}, \text { and } \\
\overline{\mathrm{RMS}}_{\text {relative }} & =(11.8 \pm 5.2) \% .
\end{aligned}
$$

Both the comparisons between the DLR DIAL and SRL and between LASE and SRL show that the largest deviations between the two instruments are typically found within the boundary layer and at the boundary layer top. In these height regions, the effect of natural

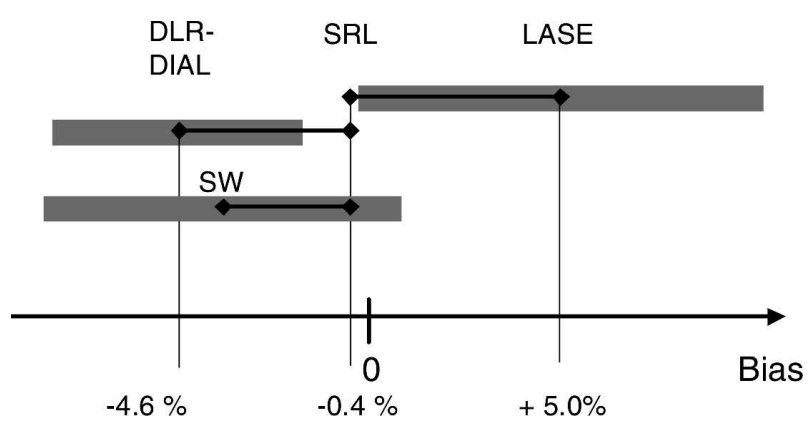

FIG. 11. Results of intercomparisons between SRL and DLR DIAL and between SRL and LASE. Horizontal bars with diamonds display the relative biases with SRL humidity data for the height interval of 1.3-3.8 km ASL. Putting equal weight on the data reliability of each lidar instrument, results in bias values of $-4.6 \%,-0.4 \%$, and $+5.0 \%$ for DLR DIAL, SRL, and LASE, respectively. Gray boxes show the $\pm 1 \sigma$ standard deviations of the intercomparisons. The mean result of four comparisons between the SW chilled-mirror hygrometer radiosondes and SRL is also plotted. inhomogeneities of the water vapor field-especially the variability of the boundary layer-top height—on the intercomparison results is largest. Thus, the inevitable sampling differences in space and time when data measured with ground-based and airborne remote sensing instruments are compared cause the largest values of the bias and RMS deviations. Furthermore, the top of the boundary layer is also the region where the different vertical resolutions and weighting functions of two sensors have the largest effect on the comparisons. This effect, which can be attributed to vertical sampling differences, however, is smaller than the effect of horizontal sampling differences because we used data of similar vertical resolution.

The performed intercomparisons between Raman lidar and DIAL data can also be used to investigate errors that are specific to either one of these techniques. On the one hand, errors may be present in the humidity profiles measured with DIAL, where steep gradients in aerosol backscattering exist (Ansmann 1985; Ansmann and Bösenberg 1987). On the other hand, elastic signal leakage to the water vapor Raman channel may cause erroneously too high humidity values for Raman lidar measurements inside of height regions with strongly enhanced particle backscattering if the elastic signal suppression is not sufficient. We do not see either of these effects in the IHOP_2002 data we investigated. As these effects are expected at least for optically thick clouds (e.g., cumuli), we conclude that the internal quality checks of each instrument worked successfully.

We found for the height interval 1.3-3.8 km ASL the following overall results for SRL and LASE:

$$
\begin{aligned}
\overline{\operatorname{Bias}}_{\text {LASE-SRL,absolute }} & =(0.16 \pm 0.31) \mathrm{g} \mathrm{kg}^{-1}, \\
\overline{\operatorname{Bias}}_{\text {LASE-SRL,relative }} & =(5.3 \pm 5.1) \%, \\
\overline{\mathrm{RMS}}_{\text {absolute }} & =(0.64 \pm 0.37) \mathrm{g} \mathrm{kg}^{-1}, \quad \text { and } \\
\overline{\mathrm{RMS}}_{\text {relative }} & =(13.6 \pm 8.0) \%,
\end{aligned}
$$

while the comparison results for SRL and DLR DIAL are

$$
\begin{aligned}
\overline{\operatorname{Bias}}_{\text {DLR-SRL,absolute }} & =(-0.30 \pm 0.25) \mathrm{g} \mathrm{kg}^{-1}, \\
\overline{\operatorname{Bias}}_{\text {DLR-SRL,relative }} & =(-4.3 \pm 3.2) \%, \\
\overline{\mathrm{RMS}}_{\text {absolute }} & =(0.60 \pm 0.25) \mathrm{g} \mathrm{kg}^{-1}, \text { and } \\
\overline{\mathrm{RMS}}_{\text {relative }} & =(9.2 \pm 2.5) \% .
\end{aligned}
$$

The relative bias is more appropriate than the absolute bias to describe mutual deviations between lidar instruments because potential errors in the system calibration for both Raman lidar and DIAL approximately scale with the amount of water vapor. For the height interval 
of 1.3-3.8 km ASL, we conclude relative bias values of $-4.6 \%,-0.4 \%$, and $+5.0 \%$ for DLR DIAL, SRL, and LASE, respectively, putting equal weight on the data reliability of each lidar instrument so that the sum of the bias values equals zero.

We consider these overall results very satisfactory because it is a challenging effort to reach an accuracy of humidity measurements down to a 5\% level. Though the number of comparison cases that are possible with the IHOP_2002 dataset is not large, the results confirm the high and stable performance of the instruments and the low noise errors of each profile. In Part II, we discuss possible intercomparisons of the airborne DIAL instruments with the IHOP_2002 dataset.

Acknowledgments. This work was supported by the project "Measurement and Intercomparison of Active, Passive and In-situ Sensors During the International $\mathrm{H}_{2} \mathrm{O}$ Project for the Verification of the Specifications of the WALES Experiment," by the European Space Agency (ESA), Contract 16669/02/NL/FF. We acknowledge the support of many IHOP_2002 participants to this project, especially Tammy Weckwerth from NCAR and R. Michael Hardesty from NOAA.

\section{REFERENCES}

Ansmann, A., 1985: Errors in ground-based water-vapor DIAL measurements due to Doppler-broadened Rayleigh backscattering. Appl. Opt., 24, 3476-3480.

- and J. Bösenberg, 1987: Correction scheme for spectral broadening by Rayleigh scattering in differential absorption lidar measurements of water vapor in the troposphere. Appl. Opt., 26, 3026-3032.

Behrendt, A., 2005: Temperature measurements with lidar. Lidar: Range-Resolved Optical Remote Sensing of the Atmosphere, C. Weitkamp, Ed., Springer Series in Optical Sciences, Vol. 102, Springer, 273-305.

, and V. Wulfmeyer, 2003: Combining water vapor DIAL and rotational Raman temperature lidar for humidity, temperature, and particle measurements with high resolution and accuracy. Proceedings of SPIE: Lidar Remote Sensing for Industry and Environment Monitoring IV, U. N. Singh, Ed., Vol. 5154, SPIE, 61-64.

_ C. Kiemle, P. Di Girolamo, H.-S. Bauer, T. Schaberl, and V. Wulfmeyer, 2004: Measurement and intercomparison of active, passive, and in-situ-sensors during the International $\mathrm{H}_{2} \mathrm{O}$ Project for the verification of the specifications of the WALES experiment. Final Rep. ESTEC Contract 16669/02/ $\mathrm{NL} / \mathrm{FF}, 56 \mathrm{pp}$.

—_ and Coauthors, 2007: Intercomparison of water vapor data measured with lidar during IHOP_2002. Part II: Airborneto-airborne systems. J. Atmos. Oceanic Technol., 24, 22-39.

Bösenberg, J., 1998: Ground-based differential absorption lidar for water-vapor and temperature profiling. Appl. Opt., 37, 3845-3860.

Browell, E. V., and S. Ismail, 1995: First lidar measurements of water vapour and aerosols from a high-altitude aircraft. OSA
Tech. Digest, Optical Remote Sensing of the Atmosphere Paper ThA4, 212-214.

_- and Coauthors, 1997: LASE validation experiment. Advances in Atmospheric Remote Sensing with Lidar, A. Ansmann et al., Eds., Springer Verlag, 289-295.

Bruneau, D., P. Quaglia, C. Flamant, M. Meissonnier, and J. Pelon, 2001: Airborne lidar LEANDRE II for water vapor profiling in the troposphere. I: System description. Appl. Opt., 40, 3450-3461.

Di Girolamo, P., R. Marchese, D. N. Whiteman, and B. B. Demoz, 2004: Rotational Raman Lidar measurements of atmospheric temperature in the UV. Geophys. Res. Lett., 31, L01106, doi:10.1029/2003GL018342.

Ehret, G., C. Kiemle, W. Renger, and G. Simmet, 1993: Airborne remote sensing of tropospheric water vapor using a near infrared DIAL system. Appl. Opt., 32, 4534-4551.

— - A. Fix, V. Weiß, G. Poberaj, and T. Baumert, 1998: Diodelaser-seeded optical parametric oscillator for airborne water vapor DIAL application in the upper troposphere and lower stratosphere. Appl. Phys., 67B, 427-431.

— K. P. Hoinka, J. Stein, A. Fix, C. Kiemle, and G. Poberaj, 1999: Low-stratospheric water vapor measured by an airborne DIAL. J. Geophys. Res., 104, 31 351-31 359.

Ferrare, R. A., and Coauthors, 2002: Characterization of upper troposperic water vapour measurements during AFWEX using LASE. Proc. 21st ILRC, Lidar Remote Sensing in Atmospheric and Earth Sciences, Vol. I, Quebec, Canada, Defense R\&D Canada-Valcartier, 397-400.

sphere water vapor measurements during AFWEX using LASE. J. Atmos. Oceanic Technol., 21, 1790-1808.

Ismail, S., and E. V. Browell, 1989: Airborne and spaceborne lidar measurements of water vapor profiles: A sensitivity analysis. Appl. Opt., 28, 3603-3615.

Nagel, D., U. Leiterer, H. Dier, A. Kats, J. Reichardt, and A. Behrendt, 2001: High accuracy humidity measurements using the standardized frequency method with a research upper-air sounding system. Meteor. Z., 10 (5), 395-405.

Poberaj, G., A. Fix, A. Assioan, M. Wirth, C. Kiemle, and G. Ehret, 2002: Airborne all-solid-state DIAL for water vapor measurements in the tropopause region: System description and assessment of accuracy. Appl. Phys., 75B, 165-172.

Ponsardin, P. L., and E. V. Browell, 1997: Measurements of $\mathrm{H} 216 \mathrm{O}$ line strengths and air-induced broadenings and shifts in the 815-nm spectral regions. J. Mol. Spectrosc., 185, 58-70.

Revercomb, H. E., and Coauthors, 2003: The Atmospheric Radiation Measurement (ARM) program's water vapor intensive observation periods: Overview, accomplishments, and future challenges. Bull. Amer. Meteor. Soc., 84, 217-236.

Sabatino, D., and Coauthors, 2004: Water vapor measurements during the International $\mathrm{H}_{2} \mathrm{O}$ Project: Intercomparisons between Scanning Raman Lidar and LASE. Reviewed and Revised Papers of the 22d International Laser Radar Conference (ILRC 2004), ESA SP-561, G. Pappalardo and A. Amodeo, Eds., European Space Agency Publications Division, 435438.

Schotland, R. M., 1966: Some observations of the vertical profile of water vapor by means of a ground based optical radar. Proc. Fourth Symp. on Remote Sensing of the Environment, Ann Arbor, MI, Environmental Research Institute of Michigan, University of Michigan, 273-283.

Turner, D. D., W. F. Feltz, and R. A. Ferrare, 2000: Continuous water vapor profiles from operational ground-Based active 
and passive remote sensors. Bull. Amer. Meteor. Soc., 81, 1301-1318.

— , R. A. Ferrare, L. A. Heilman Brasseur, W. F. Feltz, and T. P. Tooman, 2002: Automated retrievals of water vapor and aerosol profiles from an operational Raman lidar. J. Atmos. Oceanic Technol., 19, 37-50.

Wandinger, U., 2005: Raman lidar. Lidar: Range-Resolved Optical Remote Sensing of the Atmosphere, C. Weitkamp, Ed., Springer Series in Optical Sciences, Vol. 102, Springer, 241271.

Wang, J., D. J. Carlson, D. B. Parsons, T. F. Hock, D. Lauritsen, H. L. Cole, K. Beierle, and E. Chamberlain, 2003: Performance of operational radiosonde humidity sensors in direct comparison with a chilled mirror dew-point hygrometer and its climate implication. Geophys. Res. Lett., 30, 1860, doi:10.1029/2003GL016985.

Warnecke, G., 1997: Meteorologie und Umwelt. Springer-Verlag, 354 pp.

Weckwerth, T. M., and Coauthors, 2004: An overview of the International $\mathrm{H}_{2} \mathrm{O}$ Project (IHOP_2002) and some preliminary highlights. Bull. Amer. Meteor. Soc., 85, 253-277.

Whiteman, D. N., 2003a: Examination of the traditional Raman lidar technique I: Evaluating the temperature dependent lidar equations. Appl. Opt., 42, 2571-2592.

— 2003b: Examination of the traditional Raman lidar technique II: Evaluating the ratios for water vapor and aerosols. Appl. Opt., 42, 2593-2608.

- , and S. H. Melfi, 1999: Cloud liquid water, mean droplet radius and number density measurements using a Raman lidar. J. Geophys. Res., 104, 31 411-31 419.

$\_, \ldots$, and R. A. Ferrare, 1992: Raman lidar system for measurement of water vapor and aerosols in the Earth's atmosphere. Appl. Opt., 31, 3068-3082.

_ , and Coauthors, 2006a: Raman lidar measurements during the International $\mathrm{H}_{2} \mathrm{O}$ Project. Part I: Instrumentation and analysis techniques. J. Atmos. Oceanic Technol., 23, 157-169.

_ , and Coauthors, 2006b: Raman lidar measurements during the International $\mathrm{H}_{2} \mathrm{O}$ Project. Part II: Case studies. J. Atmos. Oceanic Technol., 23, 170-183.

Wulfmeyer, V., H.-S. Bauer, M. Grzeschik, A. Behrendt, F. Vandenberghe, E. V. Browell, S. Ismail, and R. A. Ferrare, 2006: Four-dimensional variational assimilation of water vapor differential absorption lidar data: The first case study within IHOP_2002. Mon. Wea. Rev., 134, 209-230. 